\title{
The long-run reversal in the long run: Insights from two centuries of international equity returns
}

\author{
Adam Zaremba ${ }^{\mathrm{a}, \mathrm{b}, *}$, Renatas Kizys ${ }^{\mathrm{c}}$, Muhammad Wajid Raza ${ }^{\mathrm{d}}$ \\ a University of Dubai, Dubai Business School, Academic City, P.O. Box: 14143, Dubai, United Arab Emirates \\ ${ }^{\mathrm{b}}$ Department of Investment and Capital Markets, Institute of Finance, Poznan University of Economics and Business, al. Niepodległości \\ 10, 61-875, Poznań, Poland \\ ${ }^{\mathrm{c}}$ Department of Banking and Finance, Southampton Business School, University of Southampton, Highfield Campus, Southampton SO17 \\ 1BJ, United Kingdom \\ d Department of Management Science, Shaheed Benazir Bhutto University Sheringal, Sheringal, District Dir(Upper), Khyber \\ Pakhtunkhwa, Pakistan
}

\section{A R T I C L E I N F O}

\section{JEL classification:}

G11

G12

G15

N20

\section{Keywords:}

Long-term reversal

Long-run reversal

Country equity indices

Early security data

Equity anomalies

Asset pricing

Return predictability

\begin{abstract}
A B S T R A C T
We perform the most comprehensive test of long-term reversal in national equity indices ever done. Having examined data from 71 countries for the years 1830 through 2019, we demonstrate a strong reversal pattern: the past long-term return negatively predicts future performance. The phenomenon is not subsumed by other established cross-sectional return patterns, including the value effect. The long-term reversal is robust to many considerations but highly unstable through time. Finally, our findings support the overreaction explanation of this anomaly.
\end{abstract}

\section{Introduction}

What goes up must come down. But has it always had to? In this article, we aim at performing a study of the long-term reversal effect over the longest time period ever done. Using a unique dataset of international equity returns going back to the year 1830 , we conduct a truly out-of-sample test of this cross-sectional phenomenon. Not only does this allow us to verify the robustness of the long-term reversal effect, but also allows us to provide some new insights into its nature.

The long-term reversal effect is the tendency of securities with high returns over the past three to five years to underperform relative to securities with low returns through the same period. Discovered originally by De Bondt and Thaler (1985) in U.S. equities, it is one of the most ubiquitous asset-pricing anomalies ever documented. The decade-old global financial crisis, the sovereign bond crisis in the European Monetary Union, and less prominent financial market jitters, have spurred renewed interest in the body of research on this effect. It has been demonstrated not only in individual stocks (Baytas and Cakici, 1999; Blackburn and Cakici, 2017), but also in national equity indices (Balvers and Wu, 2006; Bhojraj and Swaminathan, 2006; Malin and Bornholt, 2013),

\footnotetext{
* Corresponding author at: Department of Investment and Capital Markets, Institute of Finance, Poznan University of Economics and Business, al. Niepodległości 10, 61-875, Poznań, Poland.

E-mail addresses: azaremba@ud.ac.ae, adam.zaremba@ue.poznan.pl (A. Zaremba), R.Kizys@soton.ac.uk (R. Kizys), wajidrazauom@sbbu.edu.pk (M.W. Raza).
} 
futures (Lubnau and Todorova, 2015), currencies (Chan, 2013), and commodities (Bianchi et al., 2015; Chaves and Viswanathan, 2016). All of these studies relied on data spanning no more than the last several decades; thus, we greatly extend the study period.

In this paper we employ a sample of country equity indices covering 71 developed, emerging, and frontier markets for the period from 1830 to 2019. We apply a range of different tests including cross-sectional regressions, panel regressions, and examinations of portfolios from one-way and two-way sorts. Furthermore, we extend our approach to incorporate further empirical exercises to investigate the potential determinants of the long-run reversal phenomenon.

The study contributes to knowledge in four ways. First, we conduct a comprehensive out-of-sample examination of the long-run reversal effect in country equity indices. Building on the seminal papers of Balvers and Wu (2006) and Bhojraj and Swaminathan (2006) as an example, we extend their study periods of 1970-1999 by more than 150 years. It is worth noting that shorter sample periods can offer only limited insights into the long-run reversal effect. Indeed, when the sample period spans just three or four decades, and the sorting period is set to five years, the number of non-overlapping observations is very small, and it becomes harder to legitimize the quest for the long-run reversal effect. Along with the evidence that the presence of the long-run reversal effect in equity indices was questionable over last twenty years (Zaremba, 2015), this casts doubt whether the phenomenon identified in the shorter sample periods is not just a statistical artefact. To the best of our knowledge, research into the mean reversion of index returns for 17 countries by Spierdijk et al. (2012), which runs from 1900 to 2008, uses the longest sample period of any previously published study in this area. Because capital flows are demonstrated to push stock prices away from fundamentals (Vayanos and Woolley, 2013), the long-run reversal effect in international stock markets could be associated with global capital flow cycles. In this regard, Reinhart et al. (2016) identify nine global capital flow cycles from 1815 to 1918, and only five cycles from 1918 to 2015. Thus, capital flows were less stable and in the nineteenth century, which our sample period encompasses, and where the long-run reversal effect is more likely. Consequently, we use almost two centuries of data to perform sorts and portfolio tests, which allows us to obtain truly robust findings. Thus, we provide compelling evidence of a significant and strong long-run reversal effect in our dataset. Specifically, a zero-investment strategy buying (selling) an equally-weighted quintile of indices with the highest (lowest) long-term return produces a mean monthly return of $-0.38 \%$ and a nine-factor alpha of $-0.47 \%$.

Second, we verify whether the long-run return reversal is an independent asset-pricing phenomenon, not subsumed by other well-established return predictors. For example, Asness et al. (2013) link the long-run reversal effect with a broader value factor, and Fama and French (1996) argue that their three-factor model - which additionally incorporates the value factor - fully captures the long-run reversal effect. To test this claim, we control for a battery of return-predictive signals including beta, value (proxied with dividend yield), momentum, idiosyncratic risk, skewness, seasonality, bond yield, and currency return. We apply three different tests including cross-sectional regressions in the style of Fama and MacBeth (1973), panel data regressions, and bivariate sorts. We demonstrate that the long-run reversal effect is independent from well-established return-predictive signals, including equity value.

Third, we conduct extensive robustness checks that ratify the presence of the long-run reversal effect and allow us to better understand its nature. Importantly, we find that it is largely robust to alternative holding and formation periods and to the influence of calendar seasonalities, and remains strong in different subsamples. Interestingly, we also document that the effect is highly unstable over time, an aspect not studied in earlier research based on shorter time frames. Whereas in the original research period of Balvers and Wu (2006) and Bhojraj and Swaminathan (2006) a significant reversal effect is exhibited, its strength in out-of-sample periods visibly tends to fade. The effect tends to disappear for periods as long as several decades; this also applies to the most recent years. Furthermore, consistent with stock-level studies in U.S. markets, the effect is particularly pronounced in periods of elevated market volatility (McLean, 2010) and return dispersion (Stivers and Sun, 2008). From an investor's perspective, this time variability of reversal profits may pose a substantial practical challenge.

Fourth, unlike Malin and Bornholt (2013), who focused on the performance of two types of contrarian strategies (the late-stage contrarian strategy and the conventional pure contrarian strategy), or Balvers and Wu (2006), who consider jointly momentum and contrarian trading strategies, we also shed some light on the potential sources of the long-term reversal effect. Specifically, we test three major hypotheses: data mining, macroeconomic risks, and behavioural factors. Given our extensive robustness checks and the pervasiveness of the anomaly over extended time periods, we do not find the first explanation likely. Next, we conduct two separate tests concerning the macroeconomic risks hypothesis. First, we control for the key macroeconomic variables - GDP growth, inflation, and the unemployment rate - in the cross-sectional regression. However, these macroeconomic variables do not subsume the long-term reversal. Second, we replicate the test of Chordia and Shivakumar (2002). We split the total returns on equity indices into a component predicted by the macroeconomic variables and an unexpected component. We detect no evidence of long-run reversal in the predicted component and strong reversal in the unexpected component. Overall, we find no support for the macroeconomic risk-based explanations of long-term reversal. Lastly, we turn to the behavioural overreaction hypothesis. In particular, we are interested in whether a possible reason for the long-run return reversal is overshooting of fundamentals by momentum investors. Consistent with this, we find that the momentum profits reverse in the long run, a finding that supports the overreaction-based explanation of the long-term reversal effect.

Our article aims at adding to two strains of literature. First, we extend the existing studies of the long-term reversal effect, with a particular focus on country indices (e.g., Balvers et al., 2000; Balvers and Wu, 2006; Bhojraj and Swaminathan, 2006; Malin and Bornholt, 2013; Richards, 1997; Spierdijk et al., 2012). We provide new insights into its performance, predictability, robustness, stability, and relationship with other variables, such as country dividend yield, that have not previously been discussed. Second, we add to a fast-growing literature that tests asset-pricing anomalies over sample periods longer than a century. For example, Geczy and Samonov (2016, 2017, 2019) test momentum and value across different asset classes in two centuries worth of data. Chabot et al. (2008) investigate momentum in Victorian-age England, and Goetzmann and Huang (2018) examine it in imperial Russia. Greyserman and Kaminsky (2014), Lempérière et al. (2014), and Hurst et al. (2017) focus on trend following in early data, 


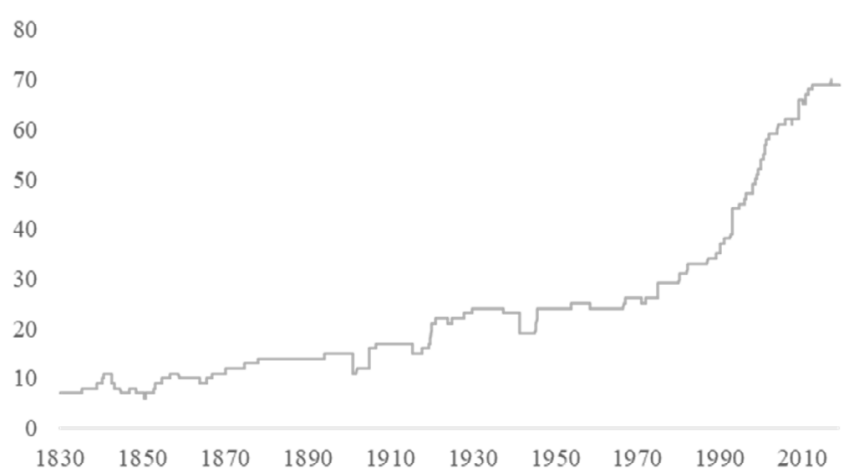

Fig. 1. Number of countries covered. Note: The figure reports the number of equity country indices included in our sample. For month $t$ we consider only the countries where both the return in month $t$ and the long-term reversal return (REV) based on months $t-60$ to $t-13$ are available.

extending for at least a century. Blitz (2016) explores low-volatility strategies dating back to 1873. Urquhart and McGroarty (2016) and Jacobsen and Zhang (2018) investigate calendar anomalies. Zaremba et al. (2019) explore long-term reversal in commodities in more than seven centuries of returns. Finally, Baltussen et al. (2019) evaluate six different strategies over the last 200 years of returns on four different asset classes. However, as far as we are concerned, no study has ever investigated the long-run reversal effect in national equity indices in a sample and timeframe comparable to ours.

The remainder of the paper proceeds as follows. Section 2 describes our data and variables. Section 3 summarizes and discusses the baseline empirical results. Section 4 focuses on the relationship between long-run reversal and other return predictors. Section 5 contains further robustness checks. Section 6 explores the sources of the long-term reversal effect. Finally, Section 7 provides conclusions.

\section{Data and variables}

We examine returns on country equity indices from 71 developed, emerging, and frontier markets. For better coverage, as in Baltussen et al. (2019), we merge two databases. Our primary source is the Datastream Global Equity Indices dataset sourced from Thomson Reuters Datastream. These are proprietary Datastream value-weighted indices that are computed following a consistent procedure and cover the largest firms in each country, representing at least $78 \%-80 \%$ of the aggregate stock market capitalization (Thomson Reuters, 2015). If the Datastream indices are not available, we use GFD Global Equity total return indices obtained from Global Financial Data (GFD). ${ }^{1}$ The GFD indices are compiled based on different historical sources, and for many countries they date back to the 19th century (GFD, 2019). ${ }^{2}$

We include a country index in our sample in a given month when we are able to compute both its return and the long-run reversal signal. Our sample period runs from February 1830 to January 2019, for a total of 2268 months. Admittedly, equity returns in several countries are available even in earlier periods, but to avoid small sample bias we arbitrarily drop the months where data are available from less than seven countries. Fig. 1 depicts the number of countries covered in our study, which increases over time. In total, our sample comprises 54,120 index-month observations.

We rely on monthly returns, which is the highest frequency of return data available for the early part of the study period. At the same time, this frequency forms a compromise between assuring a large number of observations and avoiding the effect of microstructure issues, so it constitutes the most common return interval choice in asset pricing studies (see, e.g., Waszczuk (2014) for review). Furthermore, international equity markets - especially in emerging and frontier markets - may exhibit differing economic conditions, elevated inflation rates, and volatile exchange rates. Hence, we follow Fama and French (2012, 2017), among others, and we express all the return and price data in U.S. dollars. ${ }^{3}$ To be consistent with this approach, we proxy the risk-free rate with the U.S. Treasury bill rate obtained from GFD.

The descriptive statistics of returns on the country equity indices, along with tickers to allow replicability, are reported in Table 1.

Because of the long-run character of the dataset, it suffers from two limitations outlined by Baltussen et al. (2019). The first limitation is survivorship bias (Brown et al., 1995). For example, some markets, perhaps significant in the past, might not be available in our sample. Argentina may serve as an example. Although at the beginning of the 19th century its GDP was comparable to that of Germany or France, its stock market at that time is not included in our sample. On the other hand, Goetzmann and Kim (2018),

\footnotetext{
1 According to Global Financial Data, all their total return indices are based upon data from securities collected from the original sources. If there was no dividend information available, we excluded the security from the index. Hence, although some of the indexes may theoretically omit some securities with incomplete information, there should be no systematic bias in terms of dividends. For further information on the treatment of corporate actions, see Taylor (2018).

2 Detailed information on particular indices is available upon request.

3 Notably, this is contrary to the approach of Geczy and Samonov (2017), who test the momentum effect in international equity indices and rely strongly on local currency returns. In later tests, we show that our results are robust to this methodological modification.
} 
Table 1

Country indices in the sample.

\begin{tabular}{|c|c|c|c|c|c|c|c|c|c|}
\hline Country & Datastream ticker & GFD ticker & Average & Standard deviation & Minimum & Maximum & Skewness & Kurtosis & No. of observations \\
\hline Argentina & TOTMKAR & GFTRARGSTM & 1.83 & 17.61 & -59.41 & 147.15 & 2.28 & 14.39 & 625 \\
\hline Australia & TOTMKAU & GFTRAUSSTD & 0.93 & 5.28 & -43.26 & 59.62 & 1.18 & 19.16 & 2247 \\
\hline Austria & TOTMКОЕ & GFTRAUTSTD & 0.99 & 6.38 & -34.25 & 37.29 & 0.32 & 5.44 & 589 \\
\hline Bahrain & ТОТМКВА & & 0.40 & 3.50 & -12.44 & 11.40 & 0.01 & 1.92 & 181 \\
\hline Belgium & TOTMKBG & GFTRBELSTD & 0.65 & 5.73 & -32.33 & 26.25 & 0.01 & 3.51 & 1460 \\
\hline Brazil & TOTMKBR & GFTRBRASTD & 1.12 & 10.06 & -69.38 & 89.67 & 1.02 & 10.46 & 2252 \\
\hline Bulgaria & TOTMKBL & & 1.69 & 9.95 & -36.59 & 38.72 & 0.33 & 2.68 & 219 \\
\hline Canada & TOTMKCN & GFTRCANSTD & 0.84 & 5.14 & -28.92 & 55.56 & 0.78 & 11.91 & 2260 \\
\hline Chile & TOTMKCL & GFTRCHLSTD & 2.07 & 11.06 & -62.07 & 76.44 & 1.32 & 10.29 & 528 \\
\hline China & ТОТМКСН & GFTRCHNSTD & 1.33 & 10.10 & -26.57 & 48.37 & 0.64 & 2.60 & 306 \\
\hline Colombia & ТОТМКСВ & GFTRCOLSTD & 1.06 & 9.30 & -90.75 & 49.06 & -1.83 & 24.32 & 409 \\
\hline Croatia & TOTMКСТ & & 0.59 & 7.33 & -31.07 & 32.34 & 0.18 & 4.60 & 159 \\
\hline Cyprus & ТОТМКСР & & 0.47 & 11.35 & -30.28 & 69.93 & 1.49 & 8.30 & 313 \\
\hline Czechia & TOTMKCZ & _PXTRD & 1.16 & 8.40 & -26.86 & 68.70 & 1.47 & 13.42 & 302 \\
\hline Denmark & TOTMKDK & GFTRDNKSTD & 0.64 & 4.21 & -28.51 & 23.37 & -0.03 & 6.50 & 1750 \\
\hline Egypt & TOTMKEY & TREGYSTM & 0.93 & 8.40 & -33.83 & 40.13 & 0.14 & 2.61 & 289 \\
\hline Estonia & & GFTRESTSTD & 1.68 & 9.68 & -37.74 & 40.66 & 0.22 & 4.11 & 282 \\
\hline Finland & TOTMKFN & GFTRFINSTD & 0.96 & 7.19 & -41.47 & 44.05 & 0.15 & 5.69 & 1275 \\
\hline France & TOTMKFR & GFTRFRASTD & 0.80 & 6.49 & -55.54 & 124.75 & 2.45 & 66.93 & 2267 \\
\hline Germany & TOTMKBD & GFTRDEUSTD & 0.73 & 7.87 & -75.19 & 128.82 & 2.31 & 70.05 & 2119 \\
\hline Greece & TOTMKGR & GFTRGRCSTD & 0.78 & 10.00 & -33.60 & 58.53 & 0.96 & 5.12 & 505 \\
\hline Hong Kong & ТОТМКНК & GFTRHKGSTD & 1.28 & 10.00 & -45.39 & 254.99 & 11.88 & 274.04 & 1839 \\
\hline Hungary & TOTMKHN & GFTRHUNSTD & 1.12 & 9.51 & -39.14 & 59.77 & 0.47 & 6.05 & 336 \\
\hline Iceland & & GFTRISLSTD & 0.59 & 9.18 & -74.99 & 23.70 & -3.24 & 23.01 & 199 \\
\hline India & TOTMKIN & GFTRINDSTD & 0.72 & 5.49 & -31.86 & 53.96 & 0.63 & 10.46 & 2267 \\
\hline Indonesia & TOTMKID & GFTRIDNSTD & 1.50 & 12.37 & -41.07 & 94.31 & 2.10 & 15.29 & 373 \\
\hline Iran & & TEDPIXD & 2.19 & 6.06 & -13.88 & 40.65 & 2.00 & 12.02 & 121 \\
\hline Ireland & TOTMKIR & GFTRIRLSTD & 0.68 & 4.56 & -32.29 & 47.71 & 0.60 & 15.26 & 2268 \\
\hline Israel & TOTMKIS & GFTSISRM & 0.67 & 7.45 & -62.88 & 33.37 & -1.35 & 10.07 & 840 \\
\hline Italy & TOTMKIT & GFTRITASTD & 0.93 & 8.64 & -82.62 & 59.87 & -0.19 & 15.60 & 1129 \\
\hline Japan & TOTMKJP & GFTRJPNSTD & 0.92 & 7.46 & -79.48 & 67.39 & -1.26 & 28.85 & 1254 \\
\hline Jordan & TOTMKJO & TRJORSTM & 0.61 & 5.67 & -30.37 & 29.84 & -0.02 & 5.61 & 371 \\
\hline Kuwait & TOTMККW & _DJKW30T & 0.54 & 5.31 & -18.10 & 17.42 & -0.13 & 2.11 & 181 \\
\hline Latvia & & GFTRLVASTD & 1.31 & 9.55 & -35.17 & 63.94 & 1.48 & 11.13 & 273 \\
\hline Lebanon & & _DBLCBBD & -0.25 & 3.99 & -10.76 & 10.28 & -0.02 & 0.32 & 80 \\
\hline Lithuania & & GFTRLTUSTD & 1.21 & 9.62 & -35.45 & 81.55 & 3.06 & 24.48 & 277 \\
\hline Luxembourg & TOTMKLX & GFTRLUXSTD & 1.11 & 5.65 & -27.23 & 23.16 & -0.25 & 2.92 & 409 \\
\hline Malaysia & TOTMКМY & GFTRMYSSTD & 0.85 & 8.00 & -38.99 & 46.15 & 0.25 & 3.24 & 1558 \\
\hline Malta & TOTMКМА & MSETRX & 0.91 & 5.21 & -17.48 & 24.58 & 0.55 & 2.14 & 277 \\
\hline Mauritius & & GFTRMUSSTD & 1.12 & 5.26 & -24.36 & 20.02 & 0.00 & 3.30 & 354 \\
\hline Mexico & TОТМКМХ & GFTRMEXSTD & 0.98 & 10.60 & -60.54 & 172.99 & 2.91 & 41.79 & 2263 \\
\hline Morocco & TOTMКМС & GFTRMARSTD & 1.03 & 4.86 & -13.46 & 23.58 & 0.45 & 2.39 & 298 \\
\hline Netherlands & TOTMKNL & GFTRNLDSTD & 0.82 & 5.26 & -30.91 & 33.13 & -0.42 & 4.38 & 1252 \\
\hline New Zealand & TOTMKNZ & GFTRNZLSTD & 0.75 & 5.13 & -50.00 & 31.09 & -0.71 & 12.20 & 1884 \\
\hline Nigeria & TOTMKNG & GFTRNGASTM & 1.14 & 9.33 & -70.22 & 48.14 & -0.91 & 13.86 & 373 \\
\hline Norway & TOTMKNW & GFTRNORSTD & 1.25 & 7.73 & -30.62 & 25.36 & -0.26 & 1.42 & 589 \\
\hline Oman & тОТМКОМ & & 0.41 & 4.48 & -20.68 & 15.79 & -0.48 & 3.27 & 159 \\
\hline Pakistan & ТОТМКРК & GFTSPAKM & 1.12 & 9.11 & -38.34 & 35.35 & 0.14 & 2.92 & 373 \\
\hline Peru & TOTMКРE & GFTRPERSTD & 1.14 & 6.76 & -29.40 & 31.40 & -0.04 & 3.93 & 313 \\
\hline Philippines & ТОТМКРН & GFTRPHLSTD & 1.30 & 9.10 & -33.67 & 56.38 & 0.91 & 5.96 & 445 \\
\hline Poland & ТОТМКРО & GFTRPOLSTD & 1.53 & 12.15 & -33.36 & 100.87 & 1.86 & 13.68 & 333 \\
\hline Portugal & TOTMКРТ & GFTRPRTSTD & 1.10 & 10.14 & -28.00 & 86.06 & 3.05 & 21.31 & 502 \\
\hline Qatar & TOTMKQA & _QSIUSTD & 1.21 & 8.44 & -24.31 & 45.04 & 0.67 & 4.44 & 181 \\
\hline Romania & TOTMKRM & & 1.34 & 12.98 & -43.89 & 84.96 & 1.10 & 7.58 & 265 \\
\hline Russia & TOTMKRS & GFTSRUSM & 1.99 & 13.30 & -56.61 & 48.37 & 0.07 & 2.28 & 289 \\
\hline Singapore & TOTMKSG & GFTRSGPSTD & 1.11 & 10.10 & -45.00 & 63.14 & 0.62 & 3.54 & 1136 \\
\hline Slovenia & TOTMKSJ & & 0.56 & 5.91 & -23.32 & 19.77 & -0.27 & 1.84 & 241 \\
\hline South Africa & TOTMKSA & GFTRZAFSTD & 0.84 & 7.66 & -45.10 & 152.31 & 6.85 & 137.63 & 2165 \\
\hline South Korea & ТОТМККО & GFTRKORSTD & 2.02 & 14.06 & -55.06 & 213.72 & 6.18 & 84.42 & 684 \\
\hline Spain & TOTMKES & GFTRESPSTD & 0.68 & 5.73 & -35.58 & 28.78 & -0.45 & 3.60 & 1205 \\
\hline Sri Lanka & ТОТМКСY & GFTRLKASTD & 0.95 & 8.01 & -24.05 & 38.41 & 0.81 & 2.53 & 379 \\
\hline Sweden & TOTMKSD & GFTRSWESTD & 0.84 & 5.38 & -28.47 & 27.59 & -0.23 & 3.25 & 1407 \\
\hline Switzerland & TOTMKSW & GFTRCHESTD & 0.84 & 4.78 & -28.99 & 33.63 & -0.22 & 4.27 & 1236 \\
\hline Taiwan & TOTMKTA & GFTRTWNSTD & 1.41 & 10.43 & -38.62 & 56.96 & 0.95 & 4.93 & 421 \\
\hline Thailand & TOTMКТН & GFTRTHASTD & 1.32 & 8.81 & -32.53 & 40.89 & 0.21 & 3.24 & 525 \\
\hline Turkey & TOTMKTK & GFTRTURSTD & 2.10 & 16.13 & -40.82 & 120.04 & 1.55 & 8.49 & 396 \\
\hline
\end{tabular}


Table 1 (continued).

\begin{tabular}{|c|c|c|c|c|c|c|c|c|c|}
\hline Country & Datastream ticker & GFD ticker & Average & Standard deviation & Minimum & Maximum & Skewness & Kurtosis & No. of observations \\
\hline United Arab Emirates & TOTMKAE & & 1.17 & 7.75 & -22.80 & 34.10 & 0.76 & 3.44 & 181 \\
\hline United Kingdom & TOTMKUK & GFTRGBRSTD & 0.67 & 4.40 & -28.83 & 54.94 & 0.74 & 17.07 & 2268 \\
\hline United States & TOTMKUS & GFTRUSASTD & 0.81 & 4.06 & -27.70 & 34.87 & -0.04 & 8.09 & 2268 \\
\hline Venezuela & TOTMKVE & GFTRVENSTM & 3.42 & 23.19 & -95.52 & 172.61 & 1.78 & 15.13 & 373 \\
\hline Vietnam & TOTMKVI & & 0.33 & 8.12 & -25.19 & 23.29 & -0.31 & 1.05 & 141 \\
\hline
\end{tabular}

Note. The table presents the descriptive statistics of returns on country equity indices covered in this study. The means, standard deviations, minima, and maxima are expressed in percentage terms. The second and third columns present index tickers from the Thomson Reuters Datastream and Global Financial Data databases, respectively.

who investigate the role of survivorship bias in the GFD database, point out that any bias is rather limited, and Dimson et al. (2008) argue that the combined value of Latin American stock markets did not exceed $1.5 \%$ of the world market during the 1900 s.

The second issue is data quality. Whereas the data on recent returns (from the last several decades) are generally trustworthy, the quality of early time series might be poor. If such quality issues are random, the effect on the results may manifest in two ways. First, the data become noisier. Second, the statistical significance of our tests will decrease. In other words, if the quality issues are not systematically biased, they should weaken rather than strengthen the phenomenon. In particular, they should push our results regarding a long-run reversal towards the null hypothesis.

Finally, in order to further secure our findings against the limitations of our data, we perform a battery of robustness checks that allow for alternative choices of sample and time periods.

Our key return-predictive signal, which represents the long-run reversal effect, $R E V$, is the average continuously compounded return in months $t-60$ to $t-13$. Our estimation period, i.e., the trailing 60 months with the most recent 12 months skipped, follows the measurement approach of Fama and French (1996), used later in many studies on equity anomalies (e.g., Jacobs, 2015; Hou et al., 2018) and in popular databases with factor returns (French, 2019). The last 12 months are skipped to disentangle the momentum effect of Jegadeesh and Titman (1993) from the measurement period. Notably, other studies use different ranking periods, from 36 to 60 months, with shorter periods or no periods skipped at all (McLean, 2010; Blackburn and Cakici, 2017). Our later robustness checks also demonstrate that the long-run reversal effect holds for alternative estimation periods. Finally, contrary to the existing body of research, we rely on average continuously compounded return rather than total returns in the estimation periods. This choice aims to ensure better comparability of the relevant coefficient in regression tests and does not influence the ranking of the indices in the portfolio tests.

Besides $R E V$, we use a range of additional control variables that have been demonstrated to predict future performance of country index returns. The momentum effect, MOM (Bhojraj and Swaminathan, 2006; Balvers and Wu, 2006), is represented by the average continuously compounded return in months $t-13$ to $t-1$. The value effect, VAL, (Asness et al., 1997) is measured by log dividend yield (i.e., the natural logarithm of $1+$ dividend yield) obtained from GFD. Previous studies of index return predictability have used a number of different valuation measures such as price-to-earnings or price-to-book value (see., e.g., Zaremba and Szczygielski, 2019). However, the estimation of such proxies is affected by the absence of fundamental accounting-based data for firms. Therefore, we follow Baltussen et al. (2019) and use dividend yield to capture the value effect. Stock market beta, BETA, (Frazzini and Pedersen, 2014) and idiosyncratic volatility, IVOL, (Bali and Cakici, 2010; Umutlu, 2015, 2019), are estimated from the capital asset pricing model (CAPM) (Sharpe 1964) using the trailing 60-months excess returns. The market risk factor, MKT, is proxied by the excess return on the global market portfolio, that is represented by the GFD Developed Market Index (see Section 3 for details). Each month $t$ we regress the index excess return in months $t-60$ to $t-1$ on MKT. The estimated slope coefficient represents BETA for month $t$, and the standard deviation of the residual represents IVOL. The seasonality effect, SEAS, (Keloharju et al., 2016) is the average same-calendar-month effect estimated through the previous 20 years, as available. The skewness of the return distribution, SKEW, (Harvey, 2000), is the product-momentum skewness coefficient calculated based on months $t-24$ to $t-1$. Fama and Schwert (1977) and Ang and Bekaert (2007) argue that interest rate is a strong predictor of future returns. The data on short-term rates are limited, so for better coverage we use yields on ten-year bonds (YLD) sourced from GFD. ${ }^{4}$ Finally, it may be theoretically possible that the long-run reversal effect is driven by a reversal in currency returns (Serban, 2010; Barosso and Santa-Clara, 2015). Hence, to guard against the role of currency reversal, we control for the average continuously compounded return on the foreign exchange rate (FX) through the same measurement period as used for REV (i.e., $t-60$ to $t-13$ ). The exchange rate change is computed against the U.S. dollar, which is our baseline currency throughout the study. The studies referenced above argue that the country indices with high $V A L, M O M, I V O L, S E A S$, and $Y L D$, and low BETA, SKEW, and FX outperform country indices with low VAL, MOM, IVOL, SEAS, and $Y L D$, and high BETA, SKEW, and FX.

The descriptive statistics of the major variables used in the study are reported in Table 2. Notably, Panel C reveals the pairwise correlation coefficients between different variables. We observe that REV does not correlate strongly with other variables, with one notable exception: $F X$, where the coefficients exceed 0.2 . Interestingly, the $V A L$ variable also does not exhibit visible correlations. The average Pearson's (Spearman's) cross-sectional correlation coefficients between the long-run reversal and dividend yield signals amount to only 0.101 (0.029). This observation seems quite surprising, because Asness et al. (2013), among others, argued that the value and reversal effects may be a manifestation of essentially the same phenomenon.

\footnotetext{
4 Importantly, replacing the bond yields with short-term Treasury bill yields from GFD does not visibly influence our results.
} 
Table 2

Descriptive statistics of the variables used in the study.

\begin{tabular}{|c|c|c|c|c|c|c|c|c|c|}
\hline & REV & BETA & VAL & MOM & IVOL & SKEW & SEAS & YLD & $\mathrm{FX}$ \\
\hline \multicolumn{10}{|c|}{ Panel A: Descriptive statistics of the pooled sample } \\
\hline Average & 0.006 & 0.748 & 0.044 & 0.007 & 0.048 & -0.137 & 0.007 & 0.060 & -0.004 \\
\hline Standard deviation & 0.013 & 0.567 & 0.034 & 0.026 & 0.041 & 0.906 & 0.030 & 0.195 & 0.017 \\
\hline Skewness & -0.016 & 0.803 & 7.635 & -0.536 & 2.745 & -0.465 & 1.720 & 210.735 & -6.452 \\
\hline Kurtosis & 3.198 & 3.2469467 & 140.1169 & 9.861 & 12.415 & 4.067 & 93.190 & 48104.81 & 55.868 \\
\hline Minimum & -0.074 & -2.844 & 0.000 & -0.330 & 0.001 & -4.586 & -0.693 & -0.006 & -0.347 \\
\hline 1st quartile & 0.000 & 0.340 & 0.027 & -0.005 & 0.022 & -0.567 & -0.004 & 0.037 & -0.004 \\
\hline Median & 0.006 & 0.723 & 0.039 & 0.007 & 0.037 & -0.100 & 0.006 & 0.048 & 0.000 \\
\hline 3rd quartile & 0.013 & 1.082 & 0.053 & 0.019 & 0.060 & 0.339 & 0.017 & 0.068 & 0.000 \\
\hline Maximum & 0.077 & 4.951 & 1.152 & 0.263 & 0.480 & 4.353 & 1.143 & 44.654 & 0.043 \\
\hline No. of observations & 54120 & 53818 & 67013 & 59288 & 53818 & 59356 & 58989 & 57273 & 138321 \\
\hline \multicolumn{10}{|c|}{ Panel B: Average monthly descriptive statistics } \\
\hline Average & 0.006 & 0.711 & 0.048 & 0.006 & 0.044 & -0.063 & 0.006 & 0.059 & -0.003 \\
\hline Standard deviation & 0.009 & 0.528 & 0.027 & 0.018 & 0.035 & 0.876 & 0.023 & 0.030 & 0.010 \\
\hline Skewness & -0.178 & 0.476 & 1.255 & -0.137 & 1.492 & -0.056 & -0.026 & 1.470 & -2.033 \\
\hline Kurtosis & 1.436 & 0.672 & 4.418 & 2.496 & 2.520 & 1.222 & 2.999 & 2.940 & 12.274 \\
\hline Minimum & -0.014 & -0.119 & 0.013 & -0.038 & 0.008 & -1.947 & -0.049 & 0.030 & -0.051 \\
\hline 1st quartile & 0.002 & 0.392 & 0.034 & -0.002 & 0.022 & -0.499 & -0.003 & 0.044 & -0.004 \\
\hline Median & 0.006 & 0.658 & 0.043 & 0.006 & 0.033 & -0.061 & 0.006 & 0.052 & -0.001 \\
\hline 3rd quartile & 0.010 & 0.941 & 0.055 & 0.014 & 0.052 & 0.379 & 0.014 & 0.062 & 0.001 \\
\hline Maximum & 0.024 & 1.891 & 0.141 & 0.046 & 0.145 & 1.768 & 0.061 & 0.168 & 0.008 \\
\hline No. of observations & 23.86 & 23.73 & 29.55 & 26.14 & 23.73 & 26.17 & 26.01 & 25.25 & 60.99 \\
\hline \multicolumn{10}{|c|}{ Panel C: Pairwise correlation coefficients } \\
\hline REV & & -0.023 & 0.101 & -0.015 & -0.035 & 0.036 & 0.120 & -0.064 & 0.215 \\
\hline BETA & -0.012 & & -0.154 & -0.031 & 0.078 & -0.008 & 0.002 & -0.081 & 0.037 \\
\hline VAL & 0.029 & -0.152 & & 0.013 & -0.007 & -0.011 & 0.005 & 0.151 & -0.001 \\
\hline MOM & 0.009 & -0.017 & -0.028 & & -0.008 & 0.190 & 0.075 & -0.075 & 0.007 \\
\hline IVOL & -0.053 & 0.011 & -0.026 & -0.015 & & 0.116 & -0.048 & 0.432 & -0.415 \\
\hline SKEW & -0.008 & -0.008 & -0.020 & 0.128 & 0.097 & & 0.019 & 0.006 & 0.018 \\
\hline SEAS & 0.103 & -0.001 & 0.001 & 0.058 & -0.038 & -0.002 & & -0.038 & 0.016 \\
\hline YLD & -0.083 & -0.098 & 0.154 & -0.078 & 0.434 & 0.009 & -0.039 & & -0.146 \\
\hline $\mathrm{FX}$ & 0.228 & 0.061 & -0.034 & -0.009 & -0.314 & -0.019 & 0.020 & -0.167 & \\
\hline
\end{tabular}

Note. The table shows the statistical properties of the principal variables used in this study: price reversal (REV), i.e., the average continuously compounded return in months $t-60$ to $t-13$; beta (BETA) estimated through months $t-60$ to $t-1$; the index dividend yield $(V A L)$; price momentum (MOM), i.e., the average continuously compounded return in months $t-12$ to $t-1$; idiosyncratic volatility (IVOL) estimated through months $t-60$ to $t-1$; skewness (SKEW) estimated through months $t-24$ to $t-1$; seasonality (SEAS); government bond yield (YLD); and average currency continuously compounded return in months $t-60$ to $t-13$ (FX). Panel $A$ displays the statistics based on the pooled sample of all the index-month observations; Panel $B$ presents the averages of monthly cross-sectional statistics; Panel $C$ reports time-series averages of monthly pairwise correlation coefficients between the variables The above-diagonal (below-diagonal) values are Pearson's product-moment (Spearman's rank based) correlation measures.

\section{Baseline empirical results}

We start our empirical investigations with the analysis of simple portfolios from one-way sorts. To this end, each month we rank all the indices available on $R E V$ and sort them into quintiles. We then build an equally-weighted portfolio and also form a zero-investment strategy that buys (sells) the indices with the highest (lowest) REV. Although this paper portfolio might not have been tradeable in the past - as short selling opportunities in many countries were generally unavailable - it may serve as a simple litmus test for a monotonic pattern in the cross-section of returns. ${ }^{5}$

We evaluate the portfolio returns with the single factor, three-factor and nine-factor models shown below, respectively:

$$
\begin{aligned}
& R_{t}=\alpha+\beta_{M K T} M K T_{t}+\varepsilon_{t}, \\
& R_{t}=\alpha+\beta_{M K T} M K T_{t}+\beta_{V A L} V A L_{t}+\beta_{M O M} M O M_{t}+\varepsilon_{t}, \\
& R_{t}=\alpha+\beta_{M K T} M K T_{t}+\beta_{V A L} V A L_{t}+\beta_{M O M} M O M_{t}+\beta_{B E T A} B E T A_{t}+\beta_{I V O L} I V O L_{t} \\
& +\beta_{S K E W} S K E W_{t}+\beta_{S E A S} S E A S_{t}+\beta_{F X} F X_{t}+\beta_{Y L D} Y L D_{t}+\varepsilon_{t},
\end{aligned}
$$

where $R_{t}$ is the excess return on an index in month $t, \varepsilon_{t}$ represents the random error term, and $\alpha$ (referred to as "alpha") denotes the abnormal return. $M K T_{t}, V A L_{t}, M O M_{t}, B E T A_{t}, I V O L_{t}, S K E W_{t}, S E A S_{t}, F X_{t}$, and $Y L D_{t}$ represent the return in month $t$ on the factors market, value, momentum, beta, idiosyncratic risk, skewness, seasonality, currency, and yield, respectively, and $\beta_{M K T}, \beta_{V A L}$,

\footnotetext{
5 Similar approach to testing anomalies in early asset data has been applied by, e.g., Geczy and Samonov (2016, 2017, 2019) and Baltussen et al. (2019). Also, Fama (2015) argues that cross-sectional and time-series tests should be performed jointly due to their unique insights and properties.
} 
Table 3

Statistical properties of the asset pricing factors.

\begin{tabular}{|c|c|c|c|c|c|c|c|c|c|}
\hline & MKT & VAL & MOM & BETA & IVOL & SKEW & SEAS & FX & YLD \\
\hline \multicolumn{10}{|c|}{ Panel A: Descriptive statistics } \\
\hline \multirow[t]{2}{*}{$\mathrm{R}$} & $0.34 * * *$ & $0.27 * * *$ & $0.68 * * *$ & $0.49 * * *$ & $0.24 * * *$ & -0.06 & $0.58^{* * *}$ & $0.35^{* * *}$ & $-0.14 * *$ \\
\hline & $(4.25)$ & $(2.83)$ & (6.23) & $(3.88)$ & $(2.77)$ & $(-0.60)$ & $(6.02)$ & $(4.15)$ & $(-2.19)$ \\
\hline SD & 3.65 & 4.29 & 4.71 & 5.93 & 4.47 & 4.28 & 4.26 & 4.45 & 3.33 \\
\hline SR & 0.32 & 0.22 & 0.50 & 0.29 & 0.19 & -0.05 & 0.47 & 0.27 & -0.15 \\
\hline Min & -53.43 & -48.99 & -36.98 & -42.11 & -23.83 & -65.53 & -40.93 & -19.93 & -24.93 \\
\hline Max & 22.96 & 58.57 & 64.39 & 49.40 & 58.35 & 35.25 & 61.74 & 62.11 & 17.09 \\
\hline Skew & -2.63 & 0.53 & 0.87 & 0.34 & 1.70 & -1.73 & 1.58 & 2.49 & -0.73 \\
\hline Kurt & 38.55 & 29.12 & 21.59 & 7.47 & 18.71 & 33.33 & 32.82 & 27.20 & 6.87 \\
\hline $\mathrm{N}$ & 2268 & 2176 & 2256 & 2268 & 2103 & 2268 & 2268 & 2250 & 1909 \\
\hline \multicolumn{10}{|c|}{ Panel B: Average returns by centuries } \\
\hline \multirow[t]{2}{*}{$R_{19}$} & $0.23 * *$ & 0.17 & $0.57 * * *$ & 0.02 & 0.17 & -0.23 & $0.77 * * *$ & $0.35^{* *}$ & -0.11 \\
\hline & $(2.42)$ & (1.14) & (3.10) & $(0.13)$ & $(0.87)$ & $(-1.24)$ & $(4.36)$ & $(2.05)$ & $(-1.02)$ \\
\hline \multirow[t]{2}{*}{$R_{20}$} & $0.41^{* * *}$ & $0.32 * * *$ & $0.76^{* * * *}$ & $0.68 * * *$ & $0.26^{* *}$ & 0.01 & $0.51 * * *$ & $0.34 * * *$ & $-0.21^{* *}$ \\
\hline & $(3.88)$ & $(2.70)$ & $(5.78)$ & $(3.46)$ & (2.07) & $(0.16)$ & $(4.43)$ & (2.95) & $(-1.96)$ \\
\hline \multirow[t]{2}{*}{$R_{21}$} & 0.42 & $0.28^{*}$ & $0.72 * * *$ & $1.29 * * *$ & $0.37^{* *}$ & $0.25^{*}$ & 0.21 & $0.44 * *$ & 0.21 \\
\hline & (1.51) & (1.90) & (3.24) & (4.99) & (2.06) & (1.71) & (1.26) & $(2.20)$ & $(1.00)$ \\
\hline \multicolumn{10}{|c|}{ Panel C: Correlation coefficients } \\
\hline \multirow[t]{2}{*}{ MKT } & & $-0.14^{* * *}$ & -0.02 & -0.03 & $-0.04^{*}$ & $0.07 * * *$ & 0.01 & $-0.11^{* * *}$ & $-0.12^{* * *}$ \\
\hline & & $(-6.04)$ & $(-0.72)$ & $(-1.25)$ & $(-1.69)$ & (3.18) & $(0.38)$ & $(-5.06)$ & $(-5.35)$ \\
\hline \multirow[t]{2}{*}{ VAL } & & & $-0.09 * * *$ & $0.06^{* * *}$ & $-0.13^{* * *}$ & $0.09^{* * *}$ & $-0.09 * * *$ & $-0.08^{* * *}$ & $0.07^{* * *}$ \\
\hline & & & $(-4.17)$ & $(2.82)$ & $(-5.68)$ & (3.92) & $(-3.95)$ & $(-3.53)$ & (3.27) \\
\hline \multirow[t]{2}{*}{ MOM } & & & & $0.10^{* * *}$ & $-0.12^{* * *}$ & $-0.30 * * *$ & $0.18^{* * *}$ & $0.12^{* * *}$ & 0.00 \\
\hline & & & & $(4.30)$ & $(-5.15)$ & $(-13.88)$ & (7.93) & (5.31) & $(0.05)$ \\
\hline \multirow[t]{2}{*}{ BETA } & & & & & $0.13^{* * *}$ & $0.04^{*}$ & $-0.04 *$ & $0.23^{* * *}$ & $0.17^{* * *}$ \\
\hline & & & & & (5.69) & (1.73) & $(-1.76)$ & (10.21) & $(7.51)$ \\
\hline \multirow[t]{2}{*}{ IVOL } & & & & & & $-0.05^{* *}$ & $-0.09 * * *$ & $0.45^{* * *}$ & $0.27 * * *$ \\
\hline & & & & & & $(-2.25)$ & $(-3.91)$ & (21.80) & (12.22) \\
\hline \multirow[t]{2}{*}{ SKEW } & & & & & & & $-0.22 * * *$ & $-0.13 * * *$ & $-0.06^{* * *}$ \\
\hline & & & & & & & $(-9.82)$ & $(-5.81)$ & $(-2.67)$ \\
\hline \multirow[t]{2}{*}{ SEAS } & & & & & & & & -0.02 & -0.01 \\
\hline & & & & & & & & $(-0.85)$ & $(-0.59)$ \\
\hline \multirow[t]{2}{*}{ FX } & & & & & & & & & $0.08^{* * *}$ \\
\hline & & & & & & & & & (3.72) \\
\hline
\end{tabular}

Note. The table presents the statistical properties of factor returns considered in this study. Panel A presents the descriptive statistics, Panel $B$ the average returns by centuries, and Panel $C$ the Pearson's product-moment pairwise correlation coefficients. $R$ denotes the mean monthly return, $S D$ the standard deviation of returns, Skew the skewness, Kurt the kurtosis, and Min and Max are maximum and minimum monthly observations, respectively. SR is the annualized Sharpe ratio. $N$ indicates the number of monthly observations. $R_{19}, R_{20}$, and $R_{21}$ indicate the average monthly returns for 19 th, 20th, and 21st centuries, respectively. The model factors are: market (MKT), value (VAL), price momentum (MOM), beta (BETA), idiosyncratic volatility (IVOL), skewness (SKEW), seasonality (SEAS), bond yield (YLD), and long-term currency return (FX). $R, S D$, Min, Max $R_{19}, R_{20}$, and $R_{21}$ are expressed as percentages. The numbers in brackets are $t$-statistics. The asterisks ***, and *** denote statistical significance at the $10 \%, 5 \%$, and $1 \%$ levels, respectively.

$\beta_{M O M}, \beta_{B E T A}, \beta_{I V O L}, \beta_{S K E W}, \beta_{S E A S}, \beta_{F X}$, and $\beta_{Y L D}$ denote the corresponding measures of factor exposure. The first model (1) is the standard CAPM from Sharpe (1964), with the market factor return calculated as the excess return on the GFD Developed Market Index, which represents a global equity portfolio. The second model (2) builds on the study of Asness et al. (2013), who argue that value and momentum are essential factors explaining the cross-section of returns on many asset classes. $V A L_{t}$ and $M O M_{t}$ represent the returns on zero-investment portfolios going long (short) the tertile of indices with the highest (lowest) values of $V A L$ and $M O M$, respectively. The last model (3) incorporates all the return predictive signals outlined in Section 2, and nests the models (1) and (2). $B E T A_{t}, I V O L_{t}, S K E W_{t}, S E A S_{t}, F X_{t}$, and $Y L D_{t}$ represent the returns on zero-investment strategies that go long (short) the indices with the highest (lowest) IVOL, SEAS, and YLD and the lowest (highest) BETA, SKEW, and FX. These additional factor portfolios are formed in exactly the same way as the value and momentum factors, i.e., as long-short equal-weighted tertile strategies. The only exception is the BETA factor: in this case, we closely follow the betting-against-beta formation procedure, as in Frazzini and Pedersen (2014). We sort the indices on beta, weight them according to the de-meaned rank, and go long the leveraged portfolio of low-beta countries, simultaneously shorting the deleveraged portfolio of high-beta countries. The broad nine-factor model (3) is also our default evaluation model in all further tests. ${ }^{6}$ The statistical properties of the returns on our asset pricing factors are reported in Table 3.

6 Although the nine-factor model incorporates a possibly broad set of factors, we acknowledge that it may still miss some potential return drivers. The cross-sectional return patterns linked to profitability or asset growth (Fama and French, 2015; Hou et al., 2015), which may have some parallels also at the country level (Wen, 2019), may just serve as examples. Nonetheless, due to unavailability of relevant data during the majority of our study period, we are not able to form country-level counterparts of these factors. 
Table 4

Performance of portfolios from one-way sorts on long-term return.

\begin{tabular}{|c|c|c|c|c|c|c|c|c|}
\hline & Low & 2 & 3 & 4 & High & H-L & MR & GRS \\
\hline \multicolumn{9}{|c|}{ Basic performance statistics } \\
\hline \multirow[t]{2}{*}{$\mathrm{R}$} & $0.79 * * *$ & $0.55^{* * *}$ & $0.38 * * *$ & $0.27 * * *$ & $0.41 * * *$ & $-0.38 * * *$ & 81.53 & \\
\hline & $(7.96)$ & (6.33) & (4.99) & (3.37) & $(4.64)$ & $(-3.23)$ & & \\
\hline SD & 5.23 & 3.79 & 3.82 & 3.59 & 4.54 & 5.69 & & \\
\hline SR & 0.52 & 0.50 & 0.34 & 0.26 & 0.31 & -0.23 & & \\
\hline \multirow[t]{2}{*}{$\mathrm{ER}_{\mathrm{MKT}}$} & $0.45^{* * *}$ & $0.20 * * *$ & 0.04 & -0.07 & 0.07 & & & \\
\hline & $(4.58)$ & $(3.07)$ & $(0.79)$ & $(-1.00)$ & $(0.89)$ & & & \\
\hline \multirow[t]{2}{*}{$\mathrm{ER}_{\text {MEAN }}$} & $0.24 * * *$ & 0.00 & $-0.17^{* * *}$ & $-0.28 * * *$ & $-0.14 * *$ & & & \\
\hline & $(3.18)$ & $(-0.20)$ & $(-3.43)$ & $(-5.97)$ & $(-2.20)$ & & & \\
\hline \multicolumn{9}{|c|}{ Factor model alphas } \\
\hline \multirow[t]{2}{*}{$\alpha_{\mathrm{CAPM}}$} & $0.57 * * *$ & $0.33^{* * *}$ & $0.16^{*}$ & 0.07 & $0.19 *$ & $-0.38^{* * *}$ & 63.86 & $0.00 * * *$ \\
\hline & (4.97) & (3.84) & (1.95) & $(0.79)$ & (1.89) & $(-2.87)$ & & \\
\hline \multirow[t]{2}{*}{$\alpha_{\mathrm{F} 3}$} & $0.68^{* * *}$ & $0.35^{* * *}$ & $0.19 * *$ & 0.07 & $0.24^{* *}$ & $-0.44^{* * *}$ & 71.71 & $0.00 * * *$ \\
\hline & $(5.29)$ & (3.85) & $(2.16)$ & $(0.81)$ & $(2.40)$ & $(-3.18)$ & & \\
\hline \multirow[t]{2}{*}{$\alpha_{\mathrm{F} 9}$} & $0.56^{* * *}$ & $0.35^{* * *}$ & $0.18^{*}$ & 0.09 & 0.09 & $-0.47^{* * *}$ & 35.62 & $0.00 * * *$ \\
\hline & (5.19) & $(3.56)$ & (1.85) & $(0.92)$ & $(0.85)$ & $(-3.89)$ & & \\
\hline \multicolumn{9}{|c|}{ Factor loadings } \\
\hline \multirow[t]{2}{*}{$\beta_{\mathrm{MKT}}$} & $0.65^{* * *}$ & $0.65^{* * *}$ & $0.65^{* * *}$ & $0.60 * * *$ & $0.64 * * *$ & -0.01 & & \\
\hline & $(6.71)$ & (6.93) & (6.19) & (6.31) & $(6.24)$ & $(-0.24)$ & & \\
\hline \multirow[t]{2}{*}{$\beta_{\mathrm{VAL}}$} & $-0.13^{* *}$ & 0.00 & -0.02 & -0.03 & 0.00 & 0.13 & & \\
\hline & $(-2.18)$ & $(0.05)$ & $(-0.79)$ & $(-1.24)$ & $(0.01)$ & (1.15) & & \\
\hline \multirow[t]{2}{*}{$\beta_{\mathrm{MOM}}$} & -0.03 & 0.00 & 0.01 & 0.02 & 0.00 & 0.04 & & \\
\hline & $(-0.83)$ & $(-0.20)$ & $(0.24)$ & $(0.71)$ & $(0.10)$ & $(0.61)$ & & \\
\hline \multirow[t]{2}{*}{$\beta_{\mathrm{BETA}}$} & $0.11^{* * *}$ & $0.06^{* * *}$ & $0.05^{* * *}$ & $0.08^{* * *}$ & $0.08 * * *$ & -0.03 & & \\
\hline & (3.15) & $(3.48)$ & (2.83) & (4.65) & (3.36) & $(-0.55)$ & & \\
\hline \multirow[t]{2}{*}{$\beta_{\mathrm{IVOL}}$} & $0.37 * * *$ & $0.10^{* * *}$ & $0.08^{* *}$ & $0.08^{* * *}$ & $0.44 * * *$ & 0.08 & & \\
\hline & (7.43) & (3.19) & (2.54) & $(2.82)$ & (7.45) & $(0.75)$ & & \\
\hline \multirow[t]{2}{*}{$\beta_{\text {SKEW }}$} & $0.08^{*}$ & -0.02 & 0.00 & 0.02 & 0.03 & -0.05 & & \\
\hline & (1.74) & $(-0.84)$ & $(0.09)$ & $(0.81)$ & $(0.66)$ & $(-0.72)$ & & \\
\hline \multirow[t]{2}{*}{$\beta_{\text {SEAS }}$} & -0.05 & -0.02 & -0.03 & 0.01 & 0.02 & 0.06 & & \\
\hline & $(-1.17)$ & $(-0.95)$ & $(-1.29)$ & $(0.67)$ & $(0.53)$ & (1.03) & & \\
\hline \multirow[t]{2}{*}{$\beta_{\mathrm{FX}}$} & $0.16^{* * *}$ & -0.02 & $-0.05^{*}$ & $-0.05^{* *}$ & $-0.13^{* *}$ & $-0.29 * * *$ & & \\
\hline & (3.14) & $(-0.68)$ & $(-1.70)$ & $(-2.25)$ & $(-2.40)$ & $(-2.97)$ & & \\
\hline \multirow[t]{2}{*}{$\beta_{\mathrm{YLD}}$} & 0.02 & $0.14 * * *$ & $0.13 * * *$ & $0.11^{* * *}$ & 0.04 & 0.01 & & \\
\hline & $(0.47)$ & (5.33) & $(4.32)$ & (3.48) & $(0.82)$ & $(0.18)$ & & \\
\hline $\mathrm{R}^{2}$ & 47.74 & 44.89 & 43.31 & 43.40 & 44.65 & 6.29 & & \\
\hline
\end{tabular}

Note. The table reports the performance of equal-weighted portfolios of country equity indices from sorts on $R E V$, i.e., the average continuously compounded return in months $t-60$ to $t-13$. The study period is February 1830-January 2019 (2268 monthly observations). Low (High) indicates the portfolio with the lowest (highest) $R E V$, and $\mathrm{H}-\mathrm{L}$ is the spread portfolio going long (short) the High (Low) portfolio. $R$ is the average monthly excess return, $S D$ is the standard deviation of excess returns, and $S R$ is the annualized Sharpe ratio. $E_{M K T}$ and $E R_{M E A N}$ represent de-meaned excess returns on the portfolio. To obtain $\mathrm{ER}_{\mathrm{MKT}}\left(\mathrm{ER}_{\mathrm{MEAN}}\right)$, each month we subtract the MKT return (the cross-sectional mean of the returns) from the analysed portfolio return. $\alpha_{C A P M}, \alpha_{F 9}$, and $\alpha_{F 9}$ indicate alphas from the CAPM (1), the three-factor model (2), and the eight-factor model (3), respectively. GRS is the $p$-value from the alpha-equality test of Gibbons et al. (1989), and $M R$ is the $p$-value from the test of monotonic relationship by Patton and Timmermann (2010). $\beta_{M K T}, \beta_{V A L}, \beta_{M O M}, \beta_{B E T A}, \beta_{I V O L}, \beta_{S K E W}, \beta_{S E A S}$, $\beta_{Y L D}$ and $\beta_{F X}$ are loadings of the nine-factor model on the market (MKT), value (VAL), momentum (MOM), beta (BETA), idiosyncratic volatility (IVOL), skewness (SKEW), seasonality (SEAS), bond yield (YLD), and currency long-term return $(F X)$ factors, respectively. $R^{2}$ is the time-series adjusted coefficient of determination. $R$, Vol, $\alpha_{C A P M}, \alpha_{3 F}, \alpha_{8 F}, R^{2}, G R S$, and $M R$ are expressed in percentage terms. The numbers in brackets are $t$-statistics calculated according to the bootstrap (for $R$ ) or Newey and West (1987) (for alphas) method. The asterisks *, $* *$, and *** denote statistical significance at the $10 \%, 5 \%$, and $1 \%$ levels, respectively.

To further validate the cross-sectional pattern in portfolio returns linked with the long-term reversal effect, we apply two additional tests. First, we calculate the GRS statistic of Gibbons et al. (1989). This test substantiates whether the alphas on all the cross-sectional portfolios are simultaneously equal to zero. The second check is the assessment of monotonic relationship (MR) given by Patton and Timmermann (2010). This simulation-based test examines whether there is a monotonic pattern in portfolio returns (or alphas) linked to the underlying sorting variable.

Table 4 presents the performance of the univariate portfolios formed on $R E V$. The portfolio with the highest previous long-term returns noticeably underperforms the portfolio with the lowest past returns. The average return on the long-short portfolio, denoted $H-L$ in Table 4, equals $-0.38 \%$ ( $t$-stat $=-3.23$ ). The effect remains significant after controlling for the risk factors, and the alpha of the nine-factor model (3) amounts to $-0.47 \%$ ( $t$-stat $=-3.89$ ). The zero-investment long-run reversal portfolio also does not exhibit any major factor exposure, and the regression coefficient is significant only for the currency factor. Furthermore, the long-term reversal effect is confirmed by the GRS test, in which the p-values indicate that the null hypothesis of alpha equality is strongly 
rejected. Nonetheless, the results of the MR tests suggest that the cross-sectional pattern is not strictly monotonic. Indeed, we can see that the mean returns decline monotonically from the first to the fourth portfolio, from $0.79 \%$ to $0.27 \%$, but then the average payoff on the fifth portfolio is slightly higher at $0.41 \%$. Nevertheless, the overall results of Table 4 are unequivocal: they clearly point to a negative relationship between past long-term returns and future performance. The long-run market winners markedly underperform as compared to the long-run market laggards. ${ }^{7}$

Table 4 provides also one additional insight. We calculate average de-meaned portfolio returns, obtained by subtracting the market portfolio return or an average cross-sectional return from the payoff on the analysed portfolio. This simple exercise aims to ascertain whether the abnormal returns on the long-short portfolios are driven mostly by the long side or short side of the trade. Interestingly, the de-meaned returns are higher in the case of the portfolio with the low long-run return rather than high-long run return. This observation has substantial practical implications because it suggests that a country-allocation strategy could be potentially successfully implemented in a long-only framework. This fact is important, as the short-selling opportunities - especially in small equity markets - may be sometimes limited.

\section{Long-run reversal versus other return predictors}

Having demonstrated the cross-sectional pattern in index returns stemming from the long-run reversal effect, we verify that this is a separate asset pricing signal. In particular, we are interested in checking the link between the reversal effect and the value effect. Earlier asset pricing literature presented different views of this issue. Fama and French (1996) argue that the long-run reversal is fully explained by their three-factor model incorporating the value factor, and Asness et al. (2013) regard value and reversal as manifestations of the same phenomenon. Also, in their long-term studies, Asness et al. (2015) and Baltussen et al. (2019) measure the value effect in certain asset classes simply with past long-term returns. On the other hand, Blackburn and Cakici (2017), who study international stock-level data, show that the long-term reversal effect is actually not explained by the value factor. An examination of data from over 70 countries spanning almost 200 years may shed some additional light on this issue. To check this, we apply three separate tests: (1) cross-sectional regressions in the style of Fama and MacBeth (1973), (2) panel-data regressions, and (3) an examination of portfolios from two-way dependent sorts.

\subsection{Cross-sectional regressions}

We begin with the Fama-MacBeth regressions. The aim of this exercise is to ascertain the predictive power of different variables, including $R E V$, for the cross-section of returns. To accomplish this, each month we run the regression:

$$
R_{i}=\gamma_{0}+\gamma_{R E V} R E V_{i}+\sum_{j=1}^{n} \gamma_{K} K_{i}^{j}+\varepsilon_{i},
$$

where $R_{i}$ is the return on stock $i$; $R E V_{i}$ represents the long-run reversal signal for stock $i$; $K$ represents the set of control variables as discussed in Section 2, also outlined in Section 2; $\gamma_{0}, \gamma_{R E V}$, and $\gamma_{K}$ are estimated monthly regression parameters; and $\varepsilon_{i}$ denotes the random error term. In our baseline approach, we apply the cross-sectional regressions to monthly USD log-returns on country indices. Nonetheless, for robustness, we also experiment with three alternative specifications. First, we change the $F X$ convention and replace the USD returns with local currency returns, as in Hjalmarsson (2010) and Rapach et al. (2013). Second, we follow Avramov et al. (2018) and apply risk-adjusted returns rather than raw returns in our regressions, in the style of Brennan et al. (1998). Specifically, we derive the risk-adjusted returns from a rolling 60-month regression on the MKT factor, following the method of Jacobs (2015). Third, we perform the cross-sectional regressions in an out-of-sample setting, i.e., excluding the country-month observations that were used in major earlier studies of the long-run reversal in the cross-section of country equity returns. Concretely, we exclude the markets with respective study periods covered in Balvers et al. (2000), Richards (1997), Malin and Bornholt (2013), Balvers and Wu (2006), and Bhojraj and Swaminathan (2006).

The results of the cross-sectional Fama-MacBeth regressions are summarized in Table 5. REV is a strong and robust predictor of returns across all the variants and specifications, including USD returns, local currency returns, and risk-adjusted returns. Notably, the $R E V$ coefficient is negative and significant not only in standalone regressions (specifications [1], [4], [7] and [10], as indicated in the top row of the table), but also when we control for the most established return predictors: beta, value, and momentum (specifications [2], [5], [8], and [11]), as well as all other predictive signals considered in this study (specifications [3], [6], [9], and [12]). ${ }^{8}$ The effect holds also in the out-of-sample framework reported in Panel D of Table 5. Most importantly, the REV effect is not subsumed by the VAL effect, and both variables are significant in the regression. This may suggest that these are actually two independent cross-sectional patterns, rather than different sides of the same coin. ${ }^{9}$

\footnotetext{
7 We also experiment with the 60-month sorting period with only the single most-recent month skipped, as opposed to 12 months in the baseline approach In such a scenario, the momentum effect seems to offset the long-run reversal signal, and the overall average return on the differential portfolios amounts to $-0.17 \%$ (t-stat $=-1.44$ ). However, once we control for the momentum effect in the factor pricing models, the abnormal return becomes significantly negative - the nine-factor alpha amounts to $-0.46 \%$ ( $\mathrm{t}$-stat $=-4.38$ ).

8 Besides the discussed control variables, we also consider an alternative definition of the long-run reversal relying on the whole return history. In this case, we define the long-reversal signal as the average continuously compounded return from the beginning of the sample until the current period. Nevertheless, these variables prove insignificant in the Fama-MacBeth regressions. When it is considered jointly with REV in bivariate regression similar to specification (1) in
} 
Table 5

The results of Fama-MacBeth regressions.

\begin{tabular}{|c|c|c|c|c|c|c|c|c|c|c|c|c|}
\hline & \multicolumn{3}{|c|}{ Panel A: Baseline approach } & \multicolumn{3}{|c|}{ Panel B: Local-currency returns } & \multicolumn{3}{|c|}{ Panel C: Risk-adjusted returns } & \multicolumn{3}{|c|}{ Panel D: Out-of-sample returns } \\
\hline & (1) & (2) & (3) & (4) & (5) & (6) & (7) & (8) & (9) & $(10)$ & (11) & (12) \\
\hline REV & $\begin{array}{l}-0.18^{* * *} \\
(-2.98)\end{array}$ & $\begin{array}{l}-0.24 * * * \\
(-4.35)\end{array}$ & $\begin{array}{l}-0.28 * * \\
(-2.08)\end{array}$ & $\begin{array}{l}-0.47^{* * *} \\
(-4.16)\end{array}$ & $\begin{array}{l}-0.39 * * * \\
(-4.85)\end{array}$ & $\begin{array}{l}-0.26^{* *} \\
(-1.97)\end{array}$ & $\begin{array}{l}-0.21 * * * \\
(-3.52)\end{array}$ & $\begin{array}{l}-0.26^{* * *} \\
(-5.04)\end{array}$ & $\begin{array}{l}-0.31^{* *} \\
(-2.16)\end{array}$ & $\begin{array}{l}-0.13^{*} \\
(-1.86)\end{array}$ & $\begin{array}{l}-0.20 * * * \\
(-2.82)\end{array}$ & $\begin{array}{l}-0.44 * * \\
(-2.43)\end{array}$ \\
\hline BETA & & $\begin{array}{l}0.00 \\
(-0.31)\end{array}$ & $\begin{array}{l}0.00 \\
(0.15)\end{array}$ & & $\begin{array}{l}0.00 * * \\
(-2.06)\end{array}$ & $\begin{array}{l}0.00 \\
(0.24)\end{array}$ & & $\begin{array}{l}0.00 * * * \\
(-2.82)\end{array}$ & $\begin{array}{l}0.00 \\
(-1.29)\end{array}$ & & $\begin{array}{l}0.00 \\
(-0.55)\end{array}$ & $\begin{array}{l}0.00 \\
(0.43)\end{array}$ \\
\hline VAL & & $\begin{array}{l}0.11 * * * \\
(4.25)\end{array}$ & $\begin{array}{l}0.11 * * \\
(2.20)\end{array}$ & & $\begin{array}{l}0.10^{* * *} \\
(3.50)\end{array}$ & $\begin{array}{l}0.11^{* *} \\
(2.55)\end{array}$ & & $\begin{array}{l}0.11 * * * \\
(4.09)\end{array}$ & $\begin{array}{l}0.10 * * \\
(2.20)\end{array}$ & & $\begin{array}{l}0.10 * * * \\
(3.21)\end{array}$ & $\begin{array}{l}0.10 \\
(1.62)\end{array}$ \\
\hline MOM & & $\begin{array}{l}0.23^{* * *} \\
(6.08)\end{array}$ & $\begin{array}{l}0.22^{* * *} \\
(3.64)\end{array}$ & & $\begin{array}{l}0.16^{* * *} \\
(4.08)\end{array}$ & $\begin{array}{l}0.20^{* * * *} \\
(4.62)\end{array}$ & & $\begin{array}{l}0.23^{* * * *} \\
(6.28)\end{array}$ & $\begin{array}{l}0.24^{* * *} \\
(4.35)\end{array}$ & & $\begin{array}{l}0.26^{* * * *} \\
(5.66)\end{array}$ & $\begin{array}{l}0.19^{* * *} \\
(2.25)\end{array}$ \\
\hline IVOL & & & $\begin{array}{l}-0.03 \\
(-0.85)\end{array}$ & & & $\begin{array}{l}-0.01 \\
(-0.17)\end{array}$ & & & $\begin{array}{l}-0.01 \\
(-0.27)\end{array}$ & & & $\begin{array}{l}0.05 \\
(0.78)\end{array}$ \\
\hline SKEW & & & $\begin{array}{l}0.00 \\
(-1.55)\end{array}$ & & & $\begin{array}{l}0.00 \\
(-1.20)\end{array}$ & & & $\begin{array}{l}0.00 \\
(-1.24)\end{array}$ & & & $\begin{array}{l}0.00 * \\
(-1.83)\end{array}$ \\
\hline SEAS & & & $\begin{array}{l}0.07 \\
(1.14)\end{array}$ & & & $\begin{array}{l}0.09 \\
(1.59)\end{array}$ & & & $\begin{array}{l}0.06 \\
(1.08)\end{array}$ & & & $\begin{array}{l}0.11^{*} \\
(1.78)\end{array}$ \\
\hline YLD & & & $\begin{array}{l}-0.15 \\
(-1.11)\end{array}$ & & & $\begin{array}{l}-0.08 \\
(-0.67)\end{array}$ & & & $\begin{array}{l}-0.11 \\
(-0.86)\end{array}$ & & & $\begin{array}{l}-0.14 \\
(-1.24)\end{array}$ \\
\hline FX & & & $\begin{array}{l}-0.71 \\
(-0.18)\end{array}$ & & & $\begin{array}{l}-0.02 \\
(0.00)\end{array}$ & & & $\begin{array}{l}-0.89 \\
(-0.23)\end{array}$ & & & $\begin{array}{l}-4.31 \\
(-1.24)\end{array}$ \\
\hline$\overline{\mathrm{R}^{2}}$ & 5.78 & 23.37 & 28.88 & 5.77 & 21.45 & 27.58 & 6.04 & 22.86 & 27.36 & 6.57 & 25.70 & 32.09 \\
\hline $\mathrm{N}$ & 55574 & 49577 & 39034 & 54476 & 49332 & 39034 & 54001 & 48418 & 38181 & 39080 & 33467 & 27363 \\
\hline
\end{tabular}

Note. The table displays the average slope coefficients from the cross-sectional regressions following Fama and MacBeth (1973). The dependent variables are month $t+1$ log-returns on country equity indices. The independent variables are reversal $(R E V)$, momentum (MOM), value (VAL), beta (BETA), idiosyncratic volatility (IVOL), skewness (SKEW), seasonality (SEAS), bond yield $(Y L D)$, and long-term currency return $(F X)$. $\overline{R^{2}}$ denotes the average cross-sectional adjusted coefficient of determination (in \%). $N$ indicates the number of index-month observations. The values in brackets are $t$-statistics calculated according to the Newey and West (1987) method. The asterisks *, **, and *** denote statistical significance at the $10 \%, 5 \%$, and $1 \%$ levels, respectively. Panel $A$ reports the standard approach, i.e., the regressions applied to returns expressed in U.S. dollars, Panel $B$ presents the outcomes of the regressions applied to local currency returns, and Panel $C$ shows the results for the regressions on risk-adjusted returns.

\subsection{Panel data regressions}

We now continue with panel data regressions. Petersen (2009) and Skoulakis (2008) indicate that in certain cases it might be more appropriate to employ panel regressions rather than tests in the style of Fama and MacBeth. Hence, to confirm the validity of our results in Table 6, we run two-way cluster-robust panel data regressions using the following formula (Cameron et al., 2011; Thompson, 2011):

$$
R_{i, t}=\delta_{0}+\delta_{R E V} R E V_{i, t}+\sum_{j=1}^{n} \delta_{K} K_{i, t}^{j}+\varepsilon_{i, t} .
$$

Similar to formula (4), the dependent variables are the excess returns in month $t$ on an index $i\left(R_{i, t}\right)$, and the independent variables are the reversal signal $\left(R E V_{i, t}\right)$ and the remaining control variables $\left(K_{i, t}^{j}\right)$ in month $t$. For robustness, we used both the pooled ordinary least squares (OLS) model and fixed-effects model. The outcomes are reported in Table 6.

Again, similar to the results reported in Table 5, the REV signal is associated with a negative and significant coefficient. The relationship is strong in all the specifications and, remarkably, it is not subsumed by the value effect proxied by the dividend yield.

\subsection{Bivariate sorts}

Finally, our third approach entails an examination of bivariate portfolios, loosely following the implementation of Long et al. (2018). In this approach, we build portfolios from two-way dependent sorts, aiming to investigate the role of $R E V$ after controlling for other individual variables. To this end, we perform a two-step procedure. In the first step, we rank all the countries in the sample based on different control variables-BETA, VAL, MOM, IVOL, SEAS, SKEW, FX, and YLD-and sort them into tertiles. In the second step, within each of these tertiles, we rank the indices on $R E V$, and sort into further tertiles. In the end, we obtain nine portfolios from two-way dependent sorts. Eventually, we calculate the average $R E V$ portfolio returns across the tertiles of the control variables. Also, as in our approach to the analysis of simple portfolios from one-way sorts described in Section 3 (reported in Table 3), we build long-short portfolios going long (short) the indices with the highest (lowest) $R E V$. The performance of the bivariate portfolios is reported in Table 7.

Table 5, then REV retains its significance with an average slope coefficient of -0.15 and the corresponding $t$-value of -2.29 . The detailer results are available upon request.

9 A limitation of our approach here is that the results could potentially be somewhat different for other proxies for value, like $\mathrm{P} / \mathrm{E}$ ratio or $\mathrm{P} / \mathrm{BV}$ ratio. Indeed, Kim (2012) and Zaremba and Szczygielski (2019) demonstrate that different value-based signals display slightly different properties and the dividend yield does not appear to be the most efficient one. Nonetheless, we are restricted in our ability to check this by the data availability. However, at least with respect to the dividend yield anomaly, the long-reversal is an independent asset pricing phenomenon. 
Table 6

The results of panel regressions.

\begin{tabular}{|c|c|c|c|c|c|c|}
\hline & \multicolumn{3}{|c|}{ Panel A: Pooled OLS model } & \multicolumn{3}{|c|}{ Panel B: Fixed-effects model } \\
\hline & (1) & (2) & (3) & (1) & (2) & (3) \\
\hline REV & $\begin{array}{l}-0.28^{* * *} \\
(-3.12)\end{array}$ & $\begin{array}{l}-0.26 * * * \\
(-2.66)\end{array}$ & $\begin{array}{l}-0.30 * * \\
(-2.42)\end{array}$ & $\begin{array}{l}-0.31^{* * *} \\
(-3.34)\end{array}$ & $\begin{array}{l}-0.28 * * * \\
(-2.94)\end{array}$ & $\begin{array}{l}-0.33^{* * *} \\
(-2.64)\end{array}$ \\
\hline BETA & & $\begin{array}{l}0.00 \\
(-0.93)\end{array}$ & $\begin{array}{l}0.00 \\
(-0.99)\end{array}$ & & $\begin{array}{l}0.00 \\
(-1.17)\end{array}$ & $\begin{array}{l}0.00 \\
(-1.41)\end{array}$ \\
\hline VAL & & $\begin{array}{l}0.06 * * * \\
(2.90)\end{array}$ & $\begin{array}{l}0.06^{* *} \\
(1.99)\end{array}$ & & $\begin{array}{l}0.07 * * * \\
(3.28)\end{array}$ & $\begin{array}{l}0.06 * * \\
(1.97)\end{array}$ \\
\hline MOM & & $\begin{array}{l}0.15^{* *} \\
(2.21)\end{array}$ & $\begin{array}{l}0.20 * * * \\
(2.72)\end{array}$ & & $\begin{array}{l}0.14 * * \\
(2.07)\end{array}$ & $\begin{array}{l}0.19 * * \\
(2.56)\end{array}$ \\
\hline IVOL & & & $\begin{array}{l}0.00 \\
(-0.11)\end{array}$ & & & $\begin{array}{l}0.01 \\
(0.17)\end{array}$ \\
\hline SKEW & & & $\begin{array}{l}0.00^{* *} \\
(-1.99)\end{array}$ & & & $\begin{array}{l}0.00^{*} \\
(-1.87)\end{array}$ \\
\hline SEAS & & & $\begin{array}{l}0.15^{* * *} \\
(3.54)\end{array}$ & & & $\begin{array}{l}0.14 * * * \\
(3.49)\end{array}$ \\
\hline YLD & & & $\begin{array}{l}0.04^{*} \\
(1.85)\end{array}$ & & & $\begin{array}{l}0.05^{* *} \\
(2.15)\end{array}$ \\
\hline FX & & & $\begin{array}{l}0.17 \\
(1.01)\end{array}$ & & & $\begin{array}{l}0.18 \\
(1.07)\end{array}$ \\
\hline $\mathrm{R}^{2}$ & 0.20 & 0.48 & 0.90 & 0.12 & 0.37 & 0.77 \\
\hline $\mathrm{N}$ & 55574 & 49577 & 39034 & 55574 & 49577 & 39034 \\
\hline
\end{tabular}

Note. This table reports the coefficients of the panel data regressions with the corresponding $t$-statistics estimated using two-way cluster-robust standard errors (Cameron et al., 2011; Thompson, 2011). The dependent variables are month $t+1$ log-returns on country equity indices. The independent variables are reversal (REV), momentum $(M O M)$, value $(V A L)$, beta (BETA), idiosyncratic volatility (IVOL), skewness (SKEW), and seasonality (SEAS), bond yield $(Y L D)$, and long-term currency return $(F X) . \overline{R^{2}}$ denotes the average cross-sectional coefficient of determination (in \%). $N$ indicates the number of index-month observations. The values in brackets are $t$-statistics calculated according to the Newey and West (1987) method. The asterisks *, **, and *** denote statistical significance at the $10 \%, 5 \%$, and $1 \%$ levels, respectively. Panel $A$ reports the results of the pooled ordinary least squares (OLS) model and Panel $B$ demonstrates the results of the fixed-effects model.

Table 7

Performance of portfolios from bivariate dependent sorts.

\begin{tabular}{|c|c|c|c|c|c|c|c|c|}
\hline & \multicolumn{4}{|c|}{ Panel A: Mean excess returns (R) } & \multicolumn{4}{|c|}{ Panel B: Alphas $\left(\alpha_{F 9}\right)$} \\
\hline & Low & Medium & High & H-L & Low & Medium & High & H-L \\
\hline BETA & $\begin{array}{l}0.66^{* * *} \\
(7.80)\end{array}$ & $\begin{array}{l}0.46^{* * *} \\
(5.51)\end{array}$ & $\begin{array}{l}0.37 * * * \\
(4.88)\end{array}$ & $\begin{array}{l}-0.29 * * * \\
(-3.70)\end{array}$ & $\begin{array}{l}0.46^{* * *} \\
(5.02)\end{array}$ & $\begin{array}{l}0.27 * * * \\
(2.84)\end{array}$ & $\begin{array}{l}0.07 \\
(0.74)\end{array}$ & $\begin{array}{l}-0.39 * * * \\
(-4.89)\end{array}$ \\
\hline VAL & $\begin{array}{l}0.71 * * * \\
(8.74)\end{array}$ & $\begin{array}{l}0.46^{* * *} \\
(5.29)\end{array}$ & $\begin{array}{l}0.35 * * * \\
(4.66)\end{array}$ & $\begin{array}{l}-0.36^{* * *} \\
(-4.66)\end{array}$ & $\begin{array}{l}0.48^{* * *} \\
(4.92)\end{array}$ & $\begin{array}{l}0.26^{* * *} \\
(2.66)\end{array}$ & $\begin{array}{l}0.07 \\
(0.73)\end{array}$ & $\begin{array}{l}-0.41 * * * \\
(-4.64)\end{array}$ \\
\hline MOM & $\begin{array}{l}0.63^{* * *} \\
(7.30)\end{array}$ & $\begin{array}{l}0.43^{* * *} \\
(5.12)\end{array}$ & $\begin{array}{l}0.39 * * * \\
(5.38)\end{array}$ & $\begin{array}{l}-0.24 * * * \\
(-3.23)\end{array}$ & $\begin{array}{l}0.45^{* * *} \\
(4.63)\end{array}$ & $\begin{array}{l}0.23^{* * *} \\
(2.58)\end{array}$ & $\begin{array}{l}0.10 \\
(1.09)\end{array}$ & $\begin{array}{l}-0.35^{* * *} \\
(-4.44)\end{array}$ \\
\hline IVOL & $\begin{array}{l}0.64 * * * \\
(8.50)\end{array}$ & $\begin{array}{l}0.48 * * * \\
(5.49)\end{array}$ & $\begin{array}{l}0.37 * * * \\
(4.76)\end{array}$ & $\begin{array}{l}-0.27^{* * *} \\
(-3.96)\end{array}$ & $\begin{array}{l}0.47 * * * \\
(5.00)\end{array}$ & $\begin{array}{l}0.24^{* *} \\
(2.49)\end{array}$ & $\begin{array}{l}0.09 \\
(0.96)\end{array}$ & $\begin{array}{l}-0.38^{* * *} \\
(-5.05)\end{array}$ \\
\hline SKEW & $\begin{array}{l}0.69 * * * \\
(7.85)\end{array}$ & $\begin{array}{l}0.49 * * * \\
(5.90)\end{array}$ & $\begin{array}{l}0.33 * * * \\
(4.36)\end{array}$ & $\begin{array}{l}-0.36^{* * *} \\
(-4.37)\end{array}$ & $\begin{array}{l}0.49 * * * \\
(4.99)\end{array}$ & $\begin{array}{l}0.27 * * * \\
(2.99)\end{array}$ & $\begin{array}{l}0.06 \\
(0.58)\end{array}$ & $\begin{array}{l}-0.43^{* *} \\
(-5.11)\end{array}$ \\
\hline SEAS & $\begin{array}{l}0.68 * * * \\
(8.23)\end{array}$ & $\begin{array}{l}0.45^{* * *} \\
(5.44)\end{array}$ & $\begin{array}{l}0.36 * * * \\
(4.59)\end{array}$ & $\begin{array}{l}-0.32^{* * *} \\
(-4.09)\end{array}$ & $\begin{array}{l}0.48 * * * \\
(4.88)\end{array}$ & $\begin{array}{l}0.26 * * * \\
(2.95)\end{array}$ & $\begin{array}{l}0.08 \\
(0.81)\end{array}$ & $\begin{array}{l}-0.40 * * * \\
(-4.69)\end{array}$ \\
\hline YLD & $\begin{array}{l}0.58^{* * *} \\
(7.80)\end{array}$ & $\begin{array}{l}0.45^{* * *} \\
(5.81)\end{array}$ & $\begin{array}{l}0.34 * * * \\
(4.80)\end{array}$ & $\begin{array}{l}-0.24^{* * *} \\
(-3.91)\end{array}$ & $\begin{array}{l}0.38 * * * \\
(3.75)\end{array}$ & $\begin{array}{l}0.24 * * * \\
(2.65)\end{array}$ & $\begin{array}{l}0.17^{*} \\
(1.86)\end{array}$ & $\begin{array}{l}-0.22^{* * *} \\
(-2.80)\end{array}$ \\
\hline $\mathrm{FX}$ & $\begin{array}{l}0.70 * * * \\
(8.37)\end{array}$ & $\begin{array}{l}0.45^{* * *} \\
(5.20)\end{array}$ & $\begin{array}{l}0.38 * * * \\
(4.50)\end{array}$ & $\begin{array}{l}-0.32^{* * *} \\
(-3.96)\end{array}$ & $\begin{array}{l}0.51 * * * \\
(5.35)\end{array}$ & $\begin{array}{l}0.24 * * \\
(2.51)\end{array}$ & $\begin{array}{l}0.06 \\
(0.66)\end{array}$ & $\begin{array}{l}-0.45^{* * *} \\
(-5.16)\end{array}$ \\
\hline
\end{tabular}

Note. The table shows the mean excess returns $(R)$ and the nine-factor model alphas $\left(\alpha_{F 9}\right)$, both expressed as percentages, on portfolios from two-way dependent sorts. In the first stage, the country indices are sorted into tertile portfolios based on the control variables indicated in the first column. The study period is February 1830 January 2019 (2268 monthly observations). Subsequently, the indices in each portfolio are sorted into tertiles based on $R E V$, i.e., the average continuously compounded return in months $t-60$ to $t-13$, forming nine two-way sorted equal-weighted portfolios. Finally, we calculate average equal-weighted returns on the three portfolios from sorts on $R E V$ across the tertiles from sorts on the control variables. The control variables comprise beta (BETA), value (VAL), momentum (MOM), idiosyncratic volatility (IVOL), skewness (SKEW), seasonality (SEAS), bond yield $(Y L D)$, and long-run currency return $(F X)$. High (Low) indicates the portfolios with the highest (lowest) $R E V$, and $H-L$ denotes the spread strategy going long (short) the High (Low) portfolio. The numbers in brackets are bootstrap (for returns) or Newey and West (1987) adjusted (for alphas) $t$-statistics. The asterisks *, **, and $* * *$ indicate statistical significance at the $10 \%, 5 \%$, and $1 \%$ levels, respectively.

The conclusions from the analysis of bivariate portfolios corroborate our earlier observations from Tables 5 and 6; the long-run reversal effect remains robust and strong even after controlling for the other popular return predictors. The strategy continues to 
Table 8

Alternative holding periods.

\begin{tabular}{lllll}
\hline & $\mathrm{R}$ & $t$-stat $_{\mathrm{R}}$ & $\alpha_{\mathrm{F9}}$ & $t$-stat \\
\hline 1 month & $-0.38^{* * *}$ & $(-3.23)$ & $-0.47^{* * *}$ & $(-3.89)$ \\
2 months & $-0.38^{* * *}$ & $(-3.33)$ & $-0.48^{* * *}$ & $(-4.14)$ \\
3 months & $-0.39^{* * *}$ & $(-3.57)$ & $-0.49^{* * *}$ & $(-4.36)$ \\
4 months & $-0.38^{* * *}$ & $(-3.59)$ & $-0.49^{* * *}$ & $(-4.41)$ \\
5 months & $-0.37^{* * *}$ & $(-3.52)$ & $-0.48^{* * *}$ & $(-4.41)$ \\
6 months & $-0.37^{* * *}$ & $(-3.58)$ & $-0.48^{* * *}$ & $(-4.45)$ \\
7 months & $-0.36^{* * *}$ & $(-3.56)$ & $-0.48^{* * *}$ & $(-4.44)$ \\
6 months & $-0.35^{* * *}$ & $(-3.55)$ & $-0.46^{* * *}$ & $(-4.37)$ \\
9 months & $-0.34^{* * *}$ & $(-3.50)$ & $-0.45^{* * *}$ & $(-4.35)$ \\
10 months & $-0.34^{* * *}$ & $(-3.49)$ & $-0.44^{* * *}$ & $(-4.29)$ \\
11 months & $-0.33^{* * *}$ & $(-3.45)$ & $-0.44^{* * *}$ & $(-4.28)$ \\
12 months & $-0.33^{* * *}$ & $-0.44^{* * *}$ & $(-4.30)$ \\
\hline
\end{tabular}

Note. The table shows the mean excess returns $(R)$ and the nine-factor model alphas $\left(\alpha_{F 9}\right)$, both expressed as percentages, on equal-weighted spread portfolios going long (short) the countries with the highest (lowest) REV, i.e., the average continuously compounded return in months $t-60$ to $t-13$, assuming the different holding periods indicated in the first column. The portfolios are rebalanced monthly. The study period is February 1830-January 2019 (2268 monthly observations). The numbers in brackets are bootstrap (for returns) or Newey and West (1987) adjusted (for alphas) $t$-statistics. The asterisks *, **, and *** indicate statistical significance at the $10 \%$, $5 \%$, and $1 \%$ levels, respectively.

produce negative and significant mean returns and alphas, even when we take into account the effect of the dividend yield (VAL) or the long-run currency return $(F X)$. Once again, the bivariate portfolios analysis confirms that $R E V$ is a strong return predictor, independent from the other established return-predictive variables.

\section{Further robustness checks}

So far, we have established the basic cross-sectional relationship between the past long-term returns and future performance. Indeed, in line with the earlier findings of Bhojraj and Swaminathan (2006), and Balvers and Wu (2006), among others, our extensive dataset exhibits a strong and convincing long-term reversal pattern. Now, to see how robust it is to different considerations, we apply a battery of supplementary robustness checks, specifically: (1) alternative holding period, (2) alternative formation and skip periods, (3) subsample analysis, (4) the role of monthly calendar seasonalities, (5) subperiod analysis, (6) and performance through different market states and economic conditions. Besides the simple verification of robustness, these additional analyses may help to uncover some further insights into the determinants of the long-run reversal effect.

\subsection{Alternative holding periods}

We start with alternative holding periods. Table 8 demonstrates the mean returns and nine-factor model alphas on long-short equal-weighted quintile portfolios formed on $R E V$. The portfolios are overlapping and rebalanced monthly, so, for instance, the portfolio with a three-month holding period includes equal proportions of stocks bought three months ago, two months ago, and one month ago.

A quick overview of the results in Table 8 indicates solid robustness of the long-term reversal effect to alternative holding periods. Even when the holding period is extended to 12 months, the mean returns and alphas decline only marginally by about $0.3-0.4 \%$. This phenomenon stems from the nature of the long-run reversal signal, which is persistent over time. This aspect of the long-term reversal strategy is particularly important from a practical perspective. Reducing trading frequency is one of the easiest ways to reduce trading costs. It seems that in this case, the operation could be done without harming the gross performance of the strategy. This might help to mitigate transaction costs which pose a challenge for numerous equity anomaly-based strategies (Chen and Velikov, 2019).

\subsection{Alternative formation and skip periods}

Having tested alternative holding periods, we now turn to different formation periods. In particular, we examine an array of sorting periods, from 24 to 72 months. In addition, for our basic 60-month approach, we check alternative skip periods, replacing the default 12-month window with some alternatives ranging from 1 to 36 months. Subsequently, we run a standard FamaMacBeth regression on the $R E V$ variables estimated using these alternative versions to check the robustness of cross-sectional return predictability.

The average cross-sectional regression coefficients and their corresponding $t$-statistics presented in Fig. 2 demonstrate that the reliability of the long-run reversal is independent of the choice of any particular sorting period. The coefficient is different and departs significantly from zero at a significance level not lower than $10 \%$ for all the estimation periods ranging from 31 to 72 months. The approach also works reliably for many different skip periods, from 10 to 26 months. If the skip period is shorter, the reversal effect becomes mixed with the momentum signal, so the overall result is unclear. 


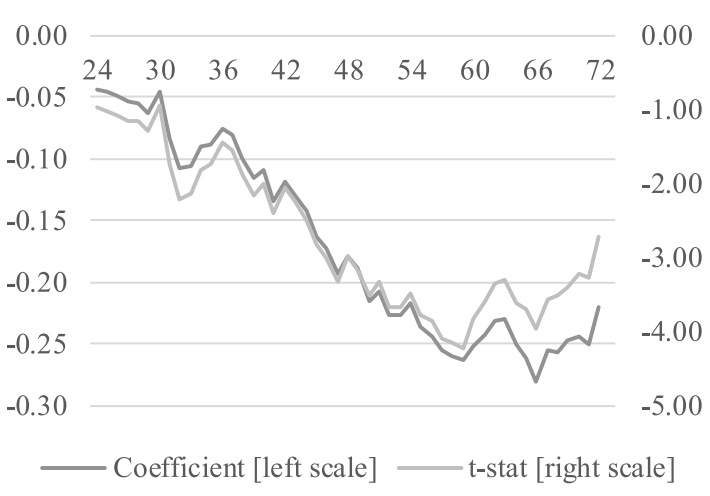

Panel A: Alternative Sorting Periods

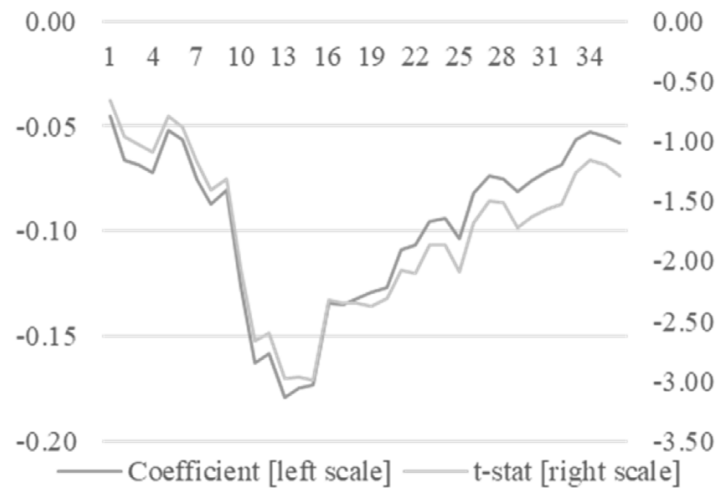

Panel B: Alternative Skip Periods

Fig. 2. Alternative sorting and skip periods. Note. The figures present the average slope coefficients from the simple Fama-MacBeth (1987) regressions where the dependent variable is the log-return in month $t$, and the independent variable is the long-run past return from month $t$-k to $t$-l. The horizontal axis in Panel A indicates the alternative estimation periods $k$. The horizontal axis in Panel B indicates the alternative skip periods $l$.

\subsection{Subsample analysis}

We continue the robustness checks with subsample analyses. The target of this exercise is to verify that the long-run reversal effect is not driven by some individual extreme markets or some specific parts of our sample. In our subsample analyses, in each month we split our full index universe in half using the median value of a range of different control variables. We source the potential control variables from the asset pricing literature, using those that tend to display some role in long-run reversal. The behavioural view on equity anomalies argues that they are manifestations of investors' limited rationality that cannot be easily arbitraged away. Hence, the long-run reversal effect should be more pronounced in market segments where there are elevated limits to arbitrage. Consistent with this, McLean (2010) proxies the limits to arbitrage with idiosyncratic volatility and shows that the long-term reversal is stronger across the stocks with high specific risk. Alternatively, Hou et al. (2013) use the $\mathrm{R}^{2}$ coefficient (sometimes referred to as synchronicity) see instead of idiosyncratic risk, and Zaremba et al. (2019) accentuate the role of total volatility. Consistent with these studies, we control, in turn, for each of these three variables: total volatility of trailing 60-month returns, and idiosyncratic risk and $\mathrm{R}^{2}$ derived from model (1) based on the same estimation period. Finally, the financing rate influences the costs of arbitrage (see, e.g., Brunnermeier and Pedersen, 2009), so we also control for the role of the YLD variable.

The limits to arbitrage form one leg of the behavioural framework; the other is investors' irrationality. While any direct measures of investor sentiment are not available for our long-run study period and geographical scope, we are able to focus on several related aspects. In this regard, Chui et al. (2010) link the strength of the momentum effect in different countries with the level of individualism in the society, and Docherty and Hurst (2018) extend it to consider the short-term orientation of the culture. As both concepts accentuate the role of overreaction in the development of momentum, and several authors have argued that the behavioural origins of momentum and reversal are inseparable phenomenon (Barberis et al., 1998; Daniel et al., 1998; Hong and Stein, 1999), we also control for the roles of individualism and short-termism. To this end, we obtain the Hofstede country scores for individualism and long-term orientation (Hofstede et al., 2010) from Hofstede Insights (2019). As in Docherty and Hurst (2018), we estimate the short-termism score as the inverse value of the long-term orientation score.

Furthermore, we also examine whether the long-term reversal effect works in countries under different economic conditions. Admittedly, the availability of reliable economic data from the 19th and early 20th century is limited, so we rely on three basic measures, all obtained from GFC: 12-month consumer price inflation rate (INFL), annual GDP growth (GDP), and an unemployment rate (UNEM). To avoid potential look-ahead bias, we lag the macro-variables by three months. ${ }^{10}$

Finally, we also control for two variables representing development of the market. First, we proxied their size with total market value at the end of preceding month. ${ }^{11}$ The smaller markets are usually less liquid, may have lower analyst coverage, and more volatile returns. Second, we differentiated the markets into developed and emerging based on their "age". The age, in this case, is defined as the time which has passed since the first market coverage in Global Financial Data or Datastream.

Having collected the control variables, we proceed with the subsample analyses as follows. Each month $t$ we split the returns by the realizations of the control variables in month $t-1$ and examine the long-run effect within the subsamples. Specifically, we sort the indices in the subsamples into tertiles by long-term reversal and evaluate the returns on these tertile portfolios. The results of all these tests are summarized in Table 9.

\footnotetext{
10 Baltussen et al. (2019) rely on a two-month lag when using inflation in some tests of early data. We check alternative lag periods, shortening them and increasing them up to 6 months, but these operations do not qualitatively change our results.

11 The data on the market size is limited to the values obtained from Datastream, i.e., to the study period $1973-2019$.
} 
Table 9

Performance of long-run reversal strategies within subsamples.

\begin{tabular}{|c|c|c|c|c|c|c|c|c|}
\hline & \multicolumn{4}{|c|}{ Mean excess return (R) } & \multicolumn{4}{|c|}{ Mean alpha $\left(\alpha_{\mathrm{F} 9}\right)$} \\
\hline & Low & Medium & High & $\mathrm{H}-\mathrm{L}$ & Low & Medium & High & H-L \\
\hline High idiosyncratic risk & $\begin{array}{l}0.83^{* * *} \\
(6.88)\end{array}$ & $\begin{array}{l}0.38 * * * \\
(3.34)\end{array}$ & $\begin{array}{l}0.41 * * * \\
(3.92)\end{array}$ & $\begin{array}{l}-0.42^{* * *} \\
(-2.99)\end{array}$ & $\begin{array}{l}0.63^{* * *} \\
(5.23)\end{array}$ & $\begin{array}{l}0.14 \\
(1.29)\end{array}$ & $\begin{array}{l}0.05 \\
(0.45)\end{array}$ & $\begin{array}{l}-0.57^{* * *} \\
(-4.00)\end{array}$ \\
\hline Low idiosyncratic risk & $\begin{array}{l}0.52 * * * \\
(7.64)\end{array}$ & $\begin{array}{l}0.39 * * * \\
(5.56)\end{array}$ & $\begin{array}{l}0.37 * * * \\
(5.05)\end{array}$ & $\begin{array}{l}-0.15^{* *} \\
(-2.49)\end{array}$ & $\begin{array}{l}0.36 * * * \\
(3.90)\end{array}$ & $\begin{array}{l}0.18^{* *} \\
(2.04)\end{array}$ & $\begin{array}{l}0.23 * * * \\
(2.59)\end{array}$ & $\begin{array}{l}-0.13^{*} \\
(-1.92)\end{array}$ \\
\hline High volatility & $\begin{array}{l}0.75 * * * \\
(6.11)\end{array}$ & $\begin{array}{l}0.46^{* * * *} \\
(3.65)\end{array}$ & $\begin{array}{l}0.38 * * * \\
(3.48)\end{array}$ & $\begin{array}{l}-0.38 * * * \\
(-2.76)\end{array}$ & $\begin{array}{l}0.59 * * * \\
(4.70)\end{array}$ & $\begin{array}{l}0.20^{*} \\
(1.66)\end{array}$ & $\begin{array}{l}0.00 \\
(-0.02)\end{array}$ & $\begin{array}{l}-0.59 * * * \\
(-4.24)\end{array}$ \\
\hline Low volatility & $\begin{array}{l}0.53 * * * \\
(8.71)\end{array}$ & $\begin{array}{l}0.37 * * * \\
(5.53)\end{array}$ & $\begin{array}{l}0.41 * * * \\
(6.68)\end{array}$ & $\begin{array}{l}-0.11 * * \\
(-2.01)\end{array}$ & $\begin{array}{l}0.37 * * * \\
(4.30)\end{array}$ & $\begin{array}{l}0.22 * * \\
(2.49)\end{array}$ & $\begin{array}{l}0.25 * * * \\
(3.14)\end{array}$ & $\begin{array}{l}-0.11 \\
(-1.64)\end{array}$ \\
\hline High $R^{2}$ coefficient & $\begin{array}{l}0.62^{* * *} \\
(6.83)\end{array}$ & $\begin{array}{l}0.48^{* * *} \\
(5.14)\end{array}$ & $\begin{array}{l}0.33^{* * *} \\
(3.93)\end{array}$ & $\begin{array}{l}-0.28^{* * *} \\
(-3.50)\end{array}$ & $\begin{array}{l}0.50 * * * \\
(4.33)\end{array}$ & $\begin{array}{l}0.29 * * * \\
(2.82)\end{array}$ & $\begin{array}{l}0.12 \\
(1.16)\end{array}$ & $\begin{array}{l}-0.37^{* * *} \\
(-3.78)\end{array}$ \\
\hline Low $\mathrm{R}^{2}$ coefficient & $\begin{array}{l}0.76^{* * *} \\
(6.75)\end{array}$ & $\begin{array}{l}0.39 * * * \\
(4.48)\end{array}$ & $\begin{array}{l}0.35^{* * *} \\
(3.67)\end{array}$ & $\begin{array}{l}-0.41^{* * *} \\
(-3.18)\end{array}$ & $\begin{array}{l}0.47 * * * \\
(4.34)\end{array}$ & $\begin{array}{l}0.25 * * \\
(2.46)\end{array}$ & $\begin{array}{l}0.00 \\
(0.01)\end{array}$ & $\begin{array}{l}-0.47^{* * *} \\
(-3.54)\end{array}$ \\
\hline High yield & $\begin{array}{l}0.52 * * * \\
(5.48)\end{array}$ & $\begin{array}{l}0.38 * * * \\
(3.56)\end{array}$ & $\begin{array}{l}0.25^{* * *} \\
(3.06)\end{array}$ & $\begin{array}{l}-0.27^{* * *} \\
(-2.93)\end{array}$ & $\begin{array}{l}0.38 * * * \\
(3.13)\end{array}$ & $\begin{array}{l}0.18^{*} \\
(1.80)\end{array}$ & $\begin{array}{l}0.11 \\
(1.04)\end{array}$ & $\begin{array}{l}-0.27^{* *} \\
(-2.32)\end{array}$ \\
\hline Low yield & $\begin{array}{l}0.61 * * * \\
(7.43)\end{array}$ & $\begin{array}{l}0.46 * * * \\
(5.98)\end{array}$ & $\begin{array}{l}0.46^{* * *} \\
(6.41)\end{array}$ & $\begin{array}{l}-0.16^{* *} \\
(-1.98)\end{array}$ & $\begin{array}{l}0.43^{* * *} \\
(4.20)\end{array}$ & $\begin{array}{l}0.26^{* * *} \\
(2.69)\end{array}$ & $\begin{array}{l}0.20 * * \\
(2.07)\end{array}$ & $\begin{array}{l}-0.23^{* *} \\
(-2.52)\end{array}$ \\
\hline High short-term orientation & $\begin{array}{l}0.66 * * * \\
(6.49)\end{array}$ & $\begin{array}{l}0.35^{* * *} \\
(4.53)\end{array}$ & $\begin{array}{l}0.39 * * * \\
(4.54)\end{array}$ & $\begin{array}{l}-0.28 * * \\
(-2.54)\end{array}$ & $\begin{array}{l}0.44 * * * \\
(3.81)\end{array}$ & $\begin{array}{l}0.19 * * \\
(2.01)\end{array}$ & $\begin{array}{l}0.19^{*} \\
(1.83)\end{array}$ & $\begin{array}{l}-0.26^{* *} \\
(-2.21)\end{array}$ \\
\hline Low short-term orientation & $\begin{array}{l}0.72^{* * *} \\
(6.81)\end{array}$ & $\begin{array}{l}0.49 * * * \\
(5.22)\end{array}$ & $\begin{array}{l}0.35^{* * *} \\
(3.51)\end{array}$ & $\begin{array}{l}-0.37^{* * *} \\
(-3.24)\end{array}$ & $\begin{array}{l}0.53^{* * *} \\
(4.44)\end{array}$ & $\begin{array}{l}0.24^{* *} \\
(2.29)\end{array}$ & $\begin{array}{l}0.00 \\
(0.00)\end{array}$ & $\begin{array}{l}-0.53 * * * \\
(-4.66)\end{array}$ \\
\hline High individualism & $\begin{array}{l}0.62 * * * \\
(8.19)\end{array}$ & $\begin{array}{l}0.45^{* * *} \\
(6.17)\end{array}$ & $\begin{array}{l}0.32 * * * \\
(3.84)\end{array}$ & $\begin{array}{l}-0.30 * * * \\
(-4.29)\end{array}$ & $\begin{array}{l}0.50 * * * \\
(5.11)\end{array}$ & $\begin{array}{l}0.25^{* * *} \\
(2.64)\end{array}$ & $\begin{array}{l}0.07 \\
(0.75)\end{array}$ & $\begin{array}{l}-0.43^{* * *} \\
(-5.08)\end{array}$ \\
\hline Low individualism & $\begin{array}{l}0.74 * * * \\
(6.31)\end{array}$ & $\begin{array}{l}0.50 * * * \\
(5.34)\end{array}$ & $\begin{array}{l}0.37 * * * \\
(3.66)\end{array}$ & $\begin{array}{l}-0.37^{* * * *} \\
(-2.86)\end{array}$ & $\begin{array}{l}0.45^{* * *} \\
(3.90)\end{array}$ & $\begin{array}{l}0.31 * * * \\
(2.70)\end{array}$ & $\begin{array}{l}0.07 \\
(0.69)\end{array}$ & $\begin{array}{l}-0.38^{* * *} \\
(-2.90)\end{array}$ \\
\hline High inflation & $\begin{array}{l}0.85 * * * \\
(7.83)\end{array}$ & $\begin{array}{l}0.32 * * * \\
(3.33)\end{array}$ & $\begin{array}{l}0.34 * * * \\
(4.44)\end{array}$ & $\begin{array}{l}-0.51 * * * \\
(-4.30)\end{array}$ & $\begin{array}{l}0.65^{* * *} \\
(5.82)\end{array}$ & $\begin{array}{l}0.09 \\
(0.86)\end{array}$ & $\begin{array}{l}0.04 \\
(0.35)\end{array}$ & $\begin{array}{l}-0.62^{* * *} \\
(-4.58)\end{array}$ \\
\hline Low inflation & $\begin{array}{l}0.60 * * * \\
(6.98)\end{array}$ & $\begin{array}{l}0.37 * * * \\
(3.73)\end{array}$ & $\begin{array}{l}0.45^{* * *} \\
(5.98)\end{array}$ & $\begin{array}{l}-0.15^{*} \\
(-1.78)\end{array}$ & $\begin{array}{l}0.45^{* * *} \\
(4.28)\end{array}$ & $\begin{array}{l}0.14 \\
(1.42)\end{array}$ & $\begin{array}{l}0.20 * * \\
(2.03)\end{array}$ & $\begin{array}{l}-0.24 * * * \\
(-2.61)\end{array}$ \\
\hline High GDP growth & $\begin{array}{l}0.69 * * * \\
(6.89)\end{array}$ & $\begin{array}{l}0.45^{* * *} \\
(4.92)\end{array}$ & $\begin{array}{l}0.39 * * * \\
(4.83)\end{array}$ & $\begin{array}{l}-0.30 * * * \\
(-3.03)\end{array}$ & $\begin{array}{l}0.43^{* * *} \\
(3.48)\end{array}$ & $\begin{array}{l}0.18^{*} \\
(1.65)\end{array}$ & $\begin{array}{l}0.11 \\
(1.05)\end{array}$ & $\begin{array}{l}-0.31 * * * \\
(-2.78)\end{array}$ \\
\hline Low GDP growth & $\begin{array}{l}0.71 * * * \\
(8.06)\end{array}$ & $\begin{array}{l}0.50 * * * \\
(4.93)\end{array}$ & $\begin{array}{l}0.42^{* * *} \\
(5.65)\end{array}$ & $\begin{array}{l}-0.28^{* * *} \\
(-3.17)\end{array}$ & $\begin{array}{l}0.55^{* * *} \\
(4.66)\end{array}$ & $\begin{array}{l}0.33^{* * *} \\
(3.28)\end{array}$ & $\begin{array}{l}0.16 \\
(1.63)\end{array}$ & $\begin{array}{l}-0.38^{* * *} \\
(-3.15)\end{array}$ \\
\hline High unemployment & $\begin{array}{l}0.71 * * * \\
(8.50)\end{array}$ & $\begin{array}{l}0.55^{* * * *} \\
(4.20)\end{array}$ & $\begin{array}{l}0.50 * * * \\
(4.11)\end{array}$ & $\begin{array}{l}-0.44 * * * \\
(-3.14)\end{array}$ & $\begin{array}{l}0.56 * * * \\
(5.17)\end{array}$ & $\begin{array}{l}0.26 * * \\
(1.97)\end{array}$ & $\begin{array}{l}0.19 \\
(1.41)\end{array}$ & $\begin{array}{l}-0.39 * * \\
(-2.46)\end{array}$ \\
\hline Low unemployment & $\begin{array}{l}0.68 \\
(0.75)\end{array}$ & $\begin{array}{l}0.41 \\
(0.56)\end{array}$ & $\begin{array}{l}0.43 \\
(0.35)\end{array}$ & $\begin{array}{l}-0.45 \\
(-0.40)\end{array}$ & $\begin{array}{l}0.43 * * * \\
(2.96)\end{array}$ & $\begin{array}{l}0.13 \\
(0.98)\end{array}$ & $\begin{array}{l}0.07 \\
(0.56)\end{array}$ & $\begin{array}{l}-0.35^{*} \\
(-1.81)\end{array}$ \\
\hline High market value & $\begin{array}{l}3.33 * * * \\
(5.63)\end{array}$ & $\begin{array}{l}2.61 * * * \\
(3.44)\end{array}$ & $\begin{array}{l}1.69 * * * \\
(2.58)\end{array}$ & $\begin{array}{l}-1.95^{* * *} \\
(-3.41)\end{array}$ & $\begin{array}{l}0.11 \\
(0.77)\end{array}$ & $\begin{array}{l}0.09 \\
(0.71)\end{array}$ & $\begin{array}{l}-0.03 \\
(-0.26)\end{array}$ & $\begin{array}{l}-0.15 \\
(-0.72)\end{array}$ \\
\hline Low market value & $\begin{array}{l}1.40 * * * \\
(5.63)\end{array}$ & $\begin{array}{l}0.79 * * * \\
(3.44)\end{array}$ & $\begin{array}{l}0.63^{* * *} \\
(2.58)\end{array}$ & $\begin{array}{l}-0.77^{* * *} \\
(-3.41)\end{array}$ & $\begin{array}{l}0.84 * * * \\
(4.12)\end{array}$ & $\begin{array}{l}0.25 \\
(1.37)\end{array}$ & $\begin{array}{l}0.24 \\
(1.40)\end{array}$ & $\begin{array}{l}-0.59 * * \\
(-2.18)\end{array}$ \\
\hline High age & $\begin{array}{l}0.72 * * * \\
(6.50)\end{array}$ & $\begin{array}{l}0.41 * * * \\
(5.24)\end{array}$ & $\begin{array}{l}0.41 * * * \\
(4.44)\end{array}$ & $\begin{array}{l}-0.31^{* * *} \\
(-2.93)\end{array}$ & $\begin{array}{l}0.55^{* * *} \\
(4.62)\end{array}$ & $\begin{array}{l}0.21^{* *} \\
(2.23)\end{array}$ & $\begin{array}{l}0.06 \\
(0.61)\end{array}$ & $\begin{array}{l}-0.48^{* * *} \\
(-4.32)\end{array}$ \\
\hline Low age & $\begin{array}{l}0.61 * * * \\
(5.64)\end{array}$ & $\begin{array}{l}0.46^{* * * *} \\
(4.42)\end{array}$ & $\begin{array}{l}0.33^{* * *} \\
(2.94)\end{array}$ & $\begin{array}{l}-0.29 * \\
(-1.92)\end{array}$ & $\begin{array}{l}0.41 * * * \\
(3.62)\end{array}$ & $\begin{array}{l}0.25^{* *} \\
(2.33)\end{array}$ & $\begin{array}{l}0.11 \\
(1.04)\end{array}$ & $\begin{array}{l}-0.30 * * \\
(-2.29)\end{array}$ \\
\hline
\end{tabular}

Note. The table shows the nine-factor model alphas $\left(\alpha_{F 9}\right)$, expressed in percentage terms, on portfolios from two-way dependent sorts on $R E V$, i.e., the average continuously compounded return in months $t-60$ to $t-13$, and additional control variables. The study period is February 1830-January 2019 (2268 monthly observations). In the first pass, each month we split the full sample into two subsamples of above-median and below-median control variables: country inflation rate, GDP growth, unemployment rate, idiosyncratic risk and $\mathrm{R}^{2}$ coefficients estimated from the CAPM model based on 60-month period, 60-month volatility of returns, bond yield, Hofstede's short-term orientation and individualism scores (Hofstede et al., 2010), market value of an index at the end of month $t-1$, and its "age", i.e., time since first coverage in Global Financial Database or Datastream. In the second pass, the portfolio is sorted into tertiles based on REV. The High (Low) are the equal-weighted portfolios from sorts on REV, and $H-L$ is the spread portfolio going long (short) the High (Low) portfolio. The numbers in brackets are bootstrap and Newey and West (1987) adjusted $t$-statistics for mean returns and alphas, respectively. The asterisks *, **, and *** indicate statistical significance at the $10 \%, 5 \%$, and $1 \%$ levels, respectively.

The long-term reversal effect proves to be robust, working effectively in almost all the possible subsamples. In consequence, the mean returns on zero-investment portfolios going long (short) the indices with the highest (lowest) REV deliver a negative and significant return in all the subsamples. Nonetheless, one can observe some variability in the magnitude of the effect. For instance, the long-run reversal profits are visibly higher across the indices of high total and idiosyncratic risk, supporting the earlier findings of McLean (2010) and Zaremba et al. (2019). Also, the effect is remarkably more pronounced in small firms than in large firms. Similar pattern is observed by Blackburn and Cakici (2017) for the stock-level data. 


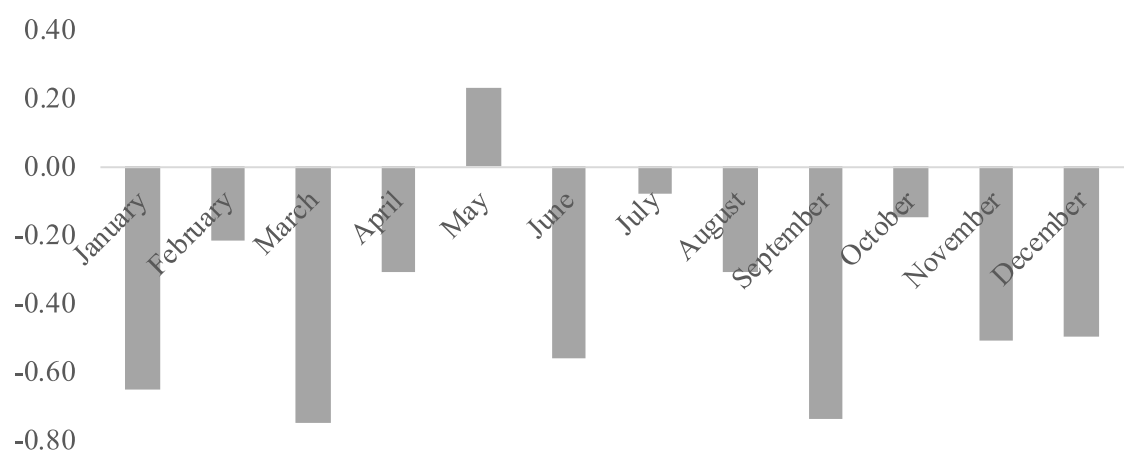

Fig. 3. Average long-term reversal returns in different calendar months. Note. The figure displays the mean returns on the long-term reversal strategies in different calendar months. The strategies analysed are zero-investment portfolios of country equity indices which go long (short) the equal-weighted quintile of countries with the highest (lowest) REV, i.e., the average continuously compounded return in months $t-60$ to $t-13$.

Table 10

Performance in different calendar months.

\begin{tabular}{lll}
\hline & $\theta_{\mathrm{M}}$ & $t$-stat \\
\hline January & -0.30 & $(-0.54)$ \\
February & 0.17 & $(0.47)$ \\
March & -0.40 & $(-0.65)$ \\
April & 0.08 & $(0.22)$ \\
May & 0.66 & $(1.63)$ \\
June & -0.19 & $(-0.47)$ \\
July & 0.33 & $(0.82)$ \\
August & 0.07 & $(0.19)$ \\
September & -0.39 & $(-1.09)$ \\
October & 0.25 & $(0.64)$ \\
November & -0.14 & $(-0.39)$ \\
December & -0.13 & $(-0.29)$ \\
\hline
\end{tabular}

Note. The table reports the slope coefficients $\theta_{M}$ (multiplied by 100) and the corresponding Newey and West (1987) adjusted $t$-statistics from the simple time-series regression model (6). The study period is February 1830-January 2019 (2268 monthly observations). The independent variables are returns on long-short equal-weighted portfolios going long (short) a quintile of indices with the highest (lowest) $R E V$, i.e., the average continuously compounded return in months $t-60$ to $t-13$. The independent variable is the dummy variable taking the value of 1 in the month indicated in the first column or zero otherwise.

\subsection{Calendar seasonalities}

Are there any seasonal patterns in the reversal effect? George and Hwang (2007), for instance, argue that a large part of the reversal effect comes solely from January returns. To check the role of any specific seasonality, we examine the performance of zero-investment equal-weighted quintile portfolios going long (short) the indices with the highest (lowest) $R E V$ in different calendar months. The mean monthly returns, displayed in Fig. 3, do not reveal any major seasonal pattern.

The effect seems to be reversed in May, but no single month seems to be solely responsible for the reversal effect. To further verify whether the contribution of any particular month significantly departs from the average, we apply an approach similar to Bouman and Jacobsen (2002), which consists of running a time-series regression with a dummy variable $M$ :

$$
R_{t}=\theta_{0}+\theta_{M} M_{K}+\varepsilon_{t},
$$

where $M_{K}$ takes the value of one in the considered month—e.g., in January—or zero otherwise, and $K$ symbolizes different calendar months. A significant slope coefficient, $\theta_{M}$, indicates abnormal returns in a particular calendar month.

The results of the dummy regression analysis, presented in Table 10, do not confirm any significant seasonal pattern. In other words, contrary to the stock-level study of long-term reversal by George and Hwang (2007), we do not detect any particular calendar month driving the long-term index reversal phenomenon.

\subsection{Performance in subperiods}

In this analysis, we are interested in the stability of the long-term reversal profit over time. Fig. 4 demonstrates the cumulative returns on the long-short equal-weighed quintile long-term reversal portfolios (Panel B), and 10-year rolling returns through our entire study period. A quick look at the charts reveals that the profits are far from stable. The strategy tends to display a decade or two of decent profits, which may be followed by another decade of significant losses. Presumably, not many investors would have 


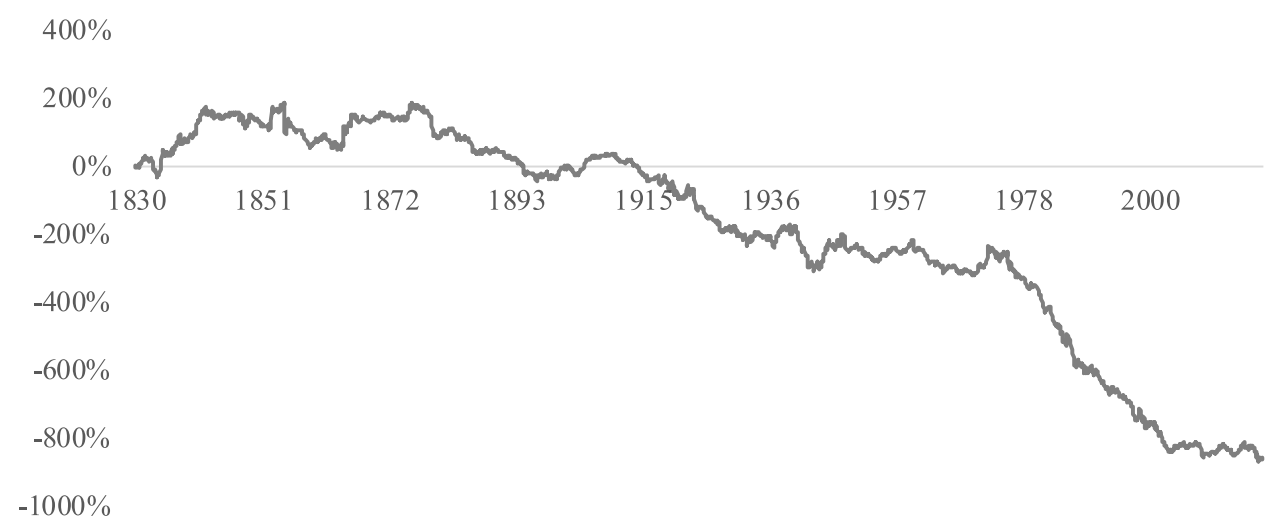

Panel A: Cumulative Returns

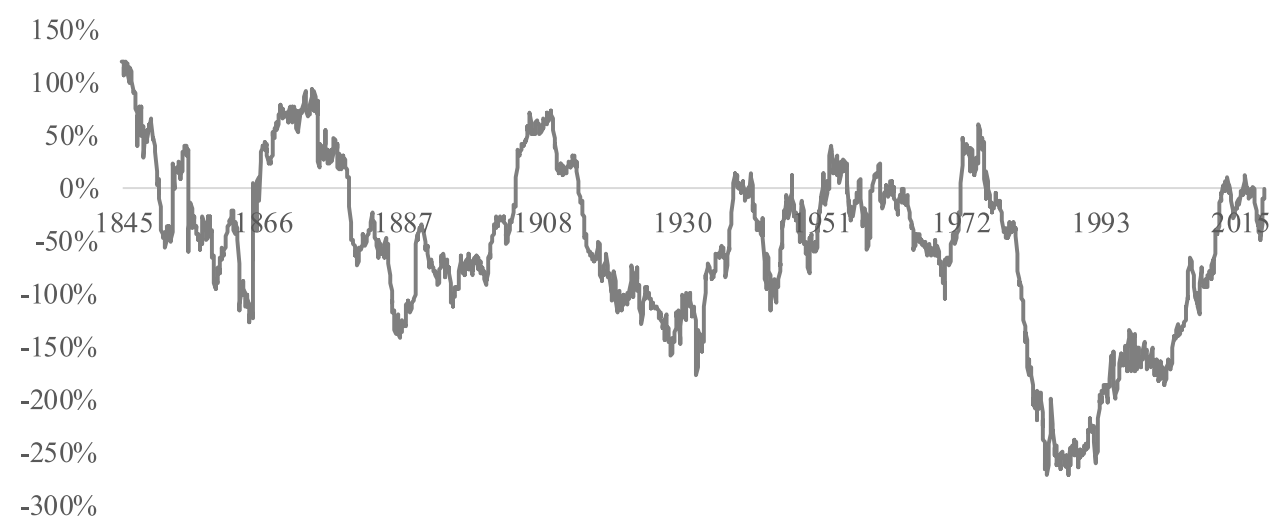

Panel B: Trailing 10-Year Returns

Fig. 4. Cumulative returns on long-term reversal portfolios. Note. The figure displays the performance of zero-investment portfolios of country equity indices which go long (short) the equal-weighted quintile of countries with the highest (lowest) $R E V$, i.e., the average continuously compounded return in months $t-60$ to $t-13$. Panel $A$ reports the returns cumulated additively, while Panel $B$ reports the trailing cumulative 10 -year return.

nerves strong enough to survive such a losing streak. As we can see in Panel A, the strategy worked pretty well from the 1970 s to the 1990s, but this was rather an exception than a rule. For example, we see no clear sign of long-run reversal within the first five decades of our sample. More importantly, the profits are far from evident in the most recent decades: in the 21st century the cumulative returns line stays flat.

Table 11 sheds additional light on this issue by displaying the mean returns and alphas in different subperiods and decades. First, Panel A shows the performance of our strategies within the original sample period of 1970 to 1999 tested by Balvers and Wu (2006) and Bhojraj and Swaminathan (2006), and in the out-of-sample period, that is, 1830-1970 and 2000-2019. The difference in terms of raw returns is dramatic, and this is also clearly visible in Fig. 4. The mean returns in the original sample period amount to $-1.24 \%$; the average out-of-sample return is $-0.22 \%$. Nevertheless, the differences may stem from different factor exposure or performance of the correlated factors, as the alphas in both periods are similar.

Panel B details further the subperiod performance by showing the returns and alphas on a decade-by-decade basis. Once again, we observe huge variability in the returns. Whereas the mean returns (alphas) in the 1980 s are as high as $-2.04 \%(-1.58 \%)$, there are numerous decades in which the strategy shows positive profits and abnormal returns. Finally, Panel C presents the performance by centuries. Notably, the relative outperformance of long-run winners by losers in the 1830s and 1840s leads to insignificance of the whole phenomenon through the entire 19th century in our study period. This instability may pose a significant practical challenge in the strategy implementation, in particular from the perspective of institutional investors whose managers need to consider short-term performance.

Table 12 reveals a subperiod analysis from a different angle. In this case, we split the time-series using the median value of a control variable to check the long-run reversal effect in subperiods of different market and economic states. Jacobs (2015) argues 
Table 11

Performance of the long-term reversal strategy through decades.

\begin{tabular}{|c|c|c|c|c|}
\hline & $\mathrm{R}$ & $t$-stat ${ }_{\mathrm{R}}$ & $\alpha_{\mathrm{F} 9}$ & $t$-stat $_{\alpha \mathrm{F} 9}$ \\
\hline \multicolumn{5}{|c|}{ Panel A: In-sample vs. out-of-sample period } \\
\hline 1970-1999 & $-1.24 * * *$ & $(-4.11)$ & $-0.30 * *$ & $(-2.11)$ \\
\hline $1830-1970 \& 2000-2019$ & $-0.22 * *$ & $(-2.03)$ & $-0.35^{* * *}$ & $(-2.66)$ \\
\hline \multicolumn{5}{|l|}{ Panel B: Results by decades } \\
\hline 1830-1839 & 0.81 & $(1.61)$ & 0.83 & $(1.33)$ \\
\hline $1840-1849$ & 0.39 & $(0.70)$ & 0.38 & $(0.80)$ \\
\hline $1850-1859$ & -0.67 & $(-0.71)$ & -0.57 & $(-0.70)$ \\
\hline $1860-1869$ & 0.58 & $(0.88)$ & -0.36 & $(-0.88)$ \\
\hline $1870-1879$ & -0.29 & $(-0.73)$ & 0.17 & $(0.50)$ \\
\hline $1880-1889$ & -0.44 & $(-1.33)$ & -0.13 & $(-0.38)$ \\
\hline 1890-1899 & $-0.62^{*}$ & $(-1.82)$ & -0.43 & $(-1.62)$ \\
\hline 1900-1909 & $0.52 * *$ & $(2.07)$ & 0.29 & $(1.12)$ \\
\hline 1910-1919 & $-0.82 * *$ & $(-2.56)$ & $-0.96^{* * *}$ & $(-3.14)$ \\
\hline 1920-1929 & -1.06 & $(-1.64)$ & $-0.93^{* *}$ & $(-2.40)$ \\
\hline 1930-1939 & -0.06 & $(-0.14)$ & -0.39 & $(-0.85)$ \\
\hline 1940-1949 & -0.41 & $(-0.67)$ & -0.24 & $(-0.43)$ \\
\hline 1950-1959 & 0.12 & $(0.51)$ & -0.21 & $(-0.68)$ \\
\hline 1960-1969 & $-0.64 *$ & $(-1.67)$ & 0.00 & $(-0.01)$ \\
\hline 1970-1979 & -0.36 & $(-0.58)$ & -0.50 & $(-1.09)$ \\
\hline 1980-1989 & $-2.04 * * *$ & $(-3.61)$ & $-1.58 * * *$ & $(-3.87)$ \\
\hline 1990-1999 & $-1.25^{* *}$ & $(-2.51)$ & -0.42 & $(-0.90)$ \\
\hline 2000-2009 & $-0.72^{*}$ & $(-1.78)$ & -0.35 & $(-1.18)$ \\
\hline 2010-2019 & -0.14 & $(-0.37)$ & -0.05 & $(-0.19)$ \\
\hline \multicolumn{5}{|l|}{ Panel C: Results by centuries } \\
\hline 19th century & -0.03 & $(-0.06)$ & -0.02 & $(-0.07)$ \\
\hline 20th century & $-0.57 * * *$ & $(-3.47)$ & $-0.58^{* * *}$ & $(-3.22)$ \\
\hline 21st century & $-0.48^{*}$ & $(-1.73)$ & $-0.58^{*}$ & $(-1.78)$ \\
\hline
\end{tabular}

Note. The table shows the mean excess returns $(R)$ and the nine-factor model alphas $\left(\alpha_{F 9}\right)$, both expressed as percentages, on the equal-weighted spread portfolios going long (short) the countries with the highest (lowest) $R E V$, i.e., the average continuously compounded return in months $t-60$ to $t-13$ in the different time periods indicated in the first column. The study period is February 1830-January 2019 (2268 monthly observations). Panel A focuses on in-sample and out-of-sample periods relative to Balvers and Wu (2006) and Bhojraj and Swaminathan (2006). Panel B displays the performance in different decades and Panel $C$ concentrates on different centuries. The numbers in brackets are bootstrap (for returns) or Newey and West (1987) adjusted (for alphas) $t$-statistics. The asterisks *,**, and $* * *$ indicate statistical significance at the $10 \%, 5 \%$, and $1 \%$ levels, respectively.

that if the equity anomalies exist because they cannot be easily arbitraged away, they should be stronger in periods of elevated limits of arbitrage. Hence, following loosely the measures of limits to arbitrage employed by Jacobs (2015), we check the performance within above-median and below-median average cross-sectional volatility, idiosyncratic volatility, and bond yield, all defined as in Section 5.3. Exploring further the behavioural perspective, again, we do not have access to direct measures of investor sentiment, but we focus on some related issues. Cooper et al. (2004) argue that overreaction is strongest following high past returns, linking it with the performance of anomalies. We check this by defining the high (low) past returns as the above-median (below-median) trailing 24-month returns on the $M K T_{t}$ factor. Stivers and Sun (2008) and Zaremba et al. (2019) demonstrate that the reversal effect is stronger in periods of high return dispersion (i.e., of high cross-sectional standard deviation of returns). Again, we check this by dividing the study period into above-median and below-median dispersion subperiods. Finally, we also examine the performance in bull and bear months, that is the months of above-median and below-median $M K T_{t}$ factor returns. Finally, as in Section 5.3, we account for different economic conditions by calculating the average cross-sectional annual GDP growth rate, 12-month inflation rate, and the unemployment rate and using these to split the study period into halves. The outcomes of these additional subperiod analyses are presented in Table 12.

Historically, the long-run loser indices produced lower returns than long-run winner indices, but the effect was not equally strong in all states and not always significant. In line with the view of Jacobs, the phenomenon was stronger in periods of high limits to arbitrage, defined as volatility, high idiosyncratic risk, and high bond yields. Moreover, as hypothesized by Cooper et al. (2004), we observe higher absolute mean returns following high past returns than following low past returns. These conclusions from the subperiod analysis are in line with the behavioural view of long-term reversal.

Also, as in Stivers and Sun (2008) and Zaremba et al. (2019), the long-term reversal is strongly pronounced in periods of high dispersion, and almost non-existent in those of low dispersion. These findings resemble firm-level evidence from U.S. markets and results from the reversal phenomenon in commodities. Finally, the outcomes of the performance under different economic conditions are equivocal. On the one hand, the absolute mean returns are higher in times of elevated inflation and unemployment, but on the other hand, the differences between high and low GDP growth periods are rather unclear. 
Table 12

The long-term reversal effect in subperiods of different market and economic conditions.

\begin{tabular}{lllll}
\hline & $\mathrm{R}$ & $t-\mathrm{stat}_{\mathrm{R}}$ & $\alpha_{\mathrm{F} 9}$ & $t$-stat \\
\hline $\mathrm{FF} 9$ \\
\hline High volatility & $-0.57^{* * *}$ & $(-2.78)$ & $-0.64^{* * *}$ & $(-3.44)$ \\
Low volatility & $-0.19^{*}$ & $(-1.74)$ & -0.17 & $(-1.16)$ \\
High idiosyncratic risk & $-0.58^{* * *}$ & $(-3.16)$ & $-0.54^{* * *}$ & $(-3.01)$ \\
Low idiosyncratic risk & -0.18 & $(-1.17)$ & $-0.30^{*}$ & $(-1.90)$ \\
High past return & $-0.40^{* * *}$ & $(-3.12)$ & $-0.47^{* * *}$ & $(-3.45)$ \\
Low past return & -0.23 & $(-0.87)$ & -0.44 & $(-1.57)$ \\
High dispersion & $-0.75^{* * *}$ & $(-3.38)$ & $-0.78^{* * *}$ & $(-3.98)$ \\
Low dispersion & -0.01 & $(-0.35)$ & -0.09 & $(-0.74)$ \\
High current return & $-0.31^{* *}$ & $(-2.30)$ & -0.06 & $(-0.30)$ \\
Low current return & $-0.50^{* *}$ & $(-2.34)$ & -0.26 & $(-0.90)$ \\
High bond yield & $-0.57^{* * *}$ & $(-3.88)$ & $-0.75^{* * *}$ & $(-4.17)$ \\
Low bond yield & -0.19 & $(-1.06)$ & -0.19 & $(-1.11)$ \\
High inflation & $-0.75^{* * *}$ & $(-4.30)$ & $-0.53^{* * *}$ & $(-2.91)$ \\
Low inflation & -0.01 & $(-0.24)$ & $-0.28^{*}$ & $(-1.91)$ \\
High GDP & $-0.50^{* * *}$ & $(-2.63)$ & $-0.30^{*}$ & $(-1.83)$ \\
Low GDP & $-0.26^{*}$ & $(-1.70)$ & $-0.59^{* * *}$ & $(-3.15)$ \\
High unemployment & $-0.69^{* * *}$ & $(-4.17)$ & $-0.57^{* * *}$ & $(-3.41)$ \\
Low unemployment & -0.07 & $(-0.45)$ & -0.22 & $(-1.16)$ \\
\hline
\end{tabular}

Note. The table shows the mean excess returns $(R)$ and the nine-factor model alphas $\left(\alpha_{F 9}\right)$, both expressed as percentages, on equal-weighted spread portfolios going long (short) the countries with the highest (lowest) $R E V$, i.e., the average continuously compounded return in months $t-60$ to $t-1$, calculated in different subperiods. The study period is February 1830-January 2019 (2268 monthly observations), and the subperiods represent halves of the full research period. To obtain the subperiod statistics, the time-series of portfolio returns is split by a median control variable into two halves. The control variables include volatility, i.e., the average standard deviation estimated from months $t-60$ to $t-1$, the average idiosyncratic volatility estimated from months $t-60$ to $t-1$, the trailing 24-month $M K T$ return (past return), the cross-sectional dispersion of returns in month $t$, the current return the market factor $M K T$ in month $t$, the average government bond yield, the average inflation rate, the average GDP growth, and the average unemployment rate. The numbers in brackets are bootstrap (for returns) or Newey and West (1987) adjusted (for alphas) $t$-statistics. The asterisks * **, and *** indicate statistical significance at the $10 \%$, $5 \%$, and $1 \%$ levels, respectively.

\subsection{The role of data source}

In this final robustness check, we want to explore the role of data sources. Our study relies on the compilation of returns derived from two types of indices: Datastream Global Equity Indices obtained from Thomson Reuters Datastream and GFD Global Equity indices sourced from Global Financial Data. To assure that the observed patterns do not result from some undefined biases in one of the databases, we replicate the analysis of the portfolios from one-way sorts on $R E V$, formed as in Table 4, relying on returns on a single class of indices only: Datastream or GFD. Notably, the Datastream sample is much shorter, as the index history goes back only to 1973 .

This exercise, reported in Table 13, confirm the robustness of our outcomes. The long-run reversal phenomenon is clearly visible for both types of indices. In both cases, the differential portfolios display significant negative average monthly returns, amounting to $-0.69 \%(t$-stat $=-3.58)$ and $-0.40 \%(t$-stat $=-3.34)$ for Datastream and GFD respectively. The corresponding nine-factor model alphas equal $-0.55 \%(t$-stat $=-2.14)$ and $-0.51 \%(t$-stat $=-4.06)$.

\section{The sources of long-term reversal in equity indices}

In this last section, we use our long-run dataset to provide some insight into the sources of the long-term reversal effect in equity indices. In general, the asset pricing literature offers three explanations that could potentially be applicable to equity index reversal: (a) data snooping, (b) underlying risk factors, and (c) behavioural overreaction. Let us take a closer look at each of them.

The concept of data snooping is that many anomalies are actually only statistical artefacts resulting from an intensive search for patterns, and they fare poorly in out-of-sample studies (Dimson and Marsh, 1999; McLean and Pontiff, 2016; Linnainmaa and Roberts, 2018). There is no way to safeguard against this criticism other than with extensive robustness checks, especially in the period preceding the original sample. Our study demonstrates that the long-term index reversal works in different settings and is robust to many considerations. Indeed, although its performance through time is very unstable, nonetheless, as we demonstrate in Section 5.5, it is significant in the pre-sample period. Hence, we deem the data mining hypothesis not likely to be true. Therefore, we focus on the macroeconomic and behavioural explanations.

\subsection{Macroeconomic risks}

Asness et al. (2013) link the long-term reversal effect to the global value premium and, building on this, Cooper et al. (2017) examine the macroeconomic exposure of different value strategies, frequently measured with long-run reversal. They show that 
Table 13

The role of data sources: Datastream vs. global financial data.

\begin{tabular}{|c|c|c|c|c|c|c|}
\hline & Low & 2 & 3 & 4 & High & CCC \\
\hline \multicolumn{7}{|c|}{ Panel A: Datastream global equity indices } \\
\hline \multirow[t]{2}{*}{$\mathrm{R}$} & $1.19 * * *$ & $0.92^{* * *}$ & $0.83^{* * *}$ & $0.59 * * *$ & $0.49 * *$ & $-0.69 * * *$ \\
\hline & (5.45) & $(4.22)$ & (3.53) & (2.61) & (2.11) & $(-3.58)$ \\
\hline \multirow[t]{2}{*}{$\alpha_{\mathrm{F} 9}$} & $0.54 * * *$ & 0.24 & 0.21 & 0.02 & -0.01 & $-0.55^{* *}$ \\
\hline & $(2.96)$ & (1.49) & $(1.40)$ & $(0.13)$ & $(-0.04)$ & $(-2.14)$ \\
\hline \multicolumn{7}{|c|}{ Panel B: GFD global equity indices } \\
\hline \multirow[t]{2}{*}{$\mathrm{R}$} & $0.79 * * *$ & $0.52^{* * *}$ & $0.39^{* * * *}$ & $0.32 * * *$ & $0.39 * * *$ & $-0.40 * * *$ \\
\hline & (7.89) & (6.03) & (4.93) & (3.81) & $(4.40)$ & $(-3.34)$ \\
\hline \multirow[t]{2}{*}{$\alpha_{\mathrm{F} 9}$} & $0.58^{* * *}$ & $0.33^{* * *}$ & $0.17^{*}$ & 0.15 & 0.07 & $-0.51 * * *$ \\
\hline & (5.27) & (3.33) & (1.75) & (1.54) & $(0.67)$ & $(-4.06)$ \\
\hline
\end{tabular}

The table shows the mean excess returns $(R)$ and the nine-factor model alphas $\left(\alpha_{F 9}\right)$, both expressed as percentages, on equal-weighted portfolios formed on $R E V$, i.e., the average continuously compounded return in months $t-60$ to $t-1$. The calculations are performed separately for the returns on Datastream Global Equity Indices obtained from Thomson Reuters Datastream (Panel A) and GFD Global Equity indices sourced from Global Financial Data. (Panel B) The study period for Datastream Global Equity Indices is January 1973-January 2019 (553 months), and for GFD Global Equity it is February 1830-January 2019 (2268 months). Low (High) indicates the portfolio with the lowest (highest) $R E V$, and $\mathrm{H}-\mathrm{L}$ is the spread portfolio going long (short) the High (Low) portfolio. The numbers in brackets are bootstrap (for returns) or Newey and West (1987) adjusted (for alphas) $t$-statistics. The asterisks *,**, and *** indicate statistical significance at the $10 \%, 5 \%$, and $1 \%$ levels, respectively.

Table 14

The role of the macroeconomic risks for cross-sectional return predictability.

\begin{tabular}{|c|c|c|c|c|c|c|c|c|c|c|c|c|}
\hline & \multicolumn{4}{|c|}{ Panel A: Baseline approach } & \multicolumn{4}{|c|}{ Panel B: Local currency returns } & \multicolumn{4}{|c|}{ Panel C: Risk-adjusted returns } \\
\hline & (1) & (2) & (3) & (4) & (5) & (6) & (7) & (8) & (9) & $(10)$ & (11) & (12) \\
\hline REV & $\begin{array}{l}-0.16^{* *} \\
(-2.50)\end{array}$ & $\begin{array}{l}-0.22^{* * *} \\
(-3.01)\end{array}$ & $\begin{array}{l}-0.28 * * \\
(-2.40)\end{array}$ & $\begin{array}{l}-0.18^{*} \\
(-1.96)\end{array}$ & $\begin{array}{l}-0.36 * * * \\
(-3.46)\end{array}$ & $\begin{array}{l}-0.59 * * * \\
(-3.98)\end{array}$ & $\begin{array}{l}-0.50 * * * \\
(-4.38)\end{array}$ & $\begin{array}{l}-0.23^{* * *} \\
(-2.81)\end{array}$ & $\begin{array}{l}-0.14 * * \\
(-2.41)\end{array}$ & $\begin{array}{l}-0.25^{* * *} \\
(-3.64)\end{array}$ & $\begin{array}{l}-0.36^{* * *} \\
(-3.19)\end{array}$ & $\begin{array}{l}-0.21 * * \\
(-2.32)\end{array}$ \\
\hline INFL & $\begin{array}{l}-0.80 \\
(-1.15)\end{array}$ & & & $\begin{array}{l}-2.49 * \\
(-1.66)\end{array}$ & $\begin{array}{l}2.80 * * * \\
(3.51)\end{array}$ & & & $\begin{array}{l}1.30 \\
(0.83)\end{array}$ & $\begin{array}{l}0.67 \\
(0.97)\end{array}$ & & & $\begin{array}{l}-0.50 \\
(-0.36)\end{array}$ \\
\hline GDP & & $\begin{array}{l}-0.01 \\
(-1.32)\end{array}$ & & $\begin{array}{l}-0.03^{*} \\
(-1.73)\end{array}$ & & $\begin{array}{l}-0.02^{* *} \\
(-2.13)\end{array}$ & & $\begin{array}{l}-0.03^{* *} \\
(-2.08)\end{array}$ & & $\begin{array}{l}-0.01 \\
(-1.20)\end{array}$ & & $\begin{array}{l}-0.03 \\
(-1.49)\end{array}$ \\
\hline UNEM & & & $\begin{array}{l}0.03^{*} \\
(1.96)\end{array}$ & $\begin{array}{l}0.01 \\
(0.66)\end{array}$ & & & $\begin{array}{l}-0.01 \\
(-0.39)\end{array}$ & $\begin{array}{l}0.01 \\
(1.05)\end{array}$ & & & $\begin{array}{l}0.02 \\
(1.29)\end{array}$ & $\begin{array}{l}0.01 \\
(0.80)\end{array}$ \\
\hline$\overline{\mathrm{R}^{2}}$ & 12.07 & 5.73 & 4.77 & 13.28 & 14.14 & 6.56 & 4.82 & 16.12 & 12.20 & 5.74 & 4.89 & 13.19 \\
\hline $\mathrm{N}$ & 49570 & 49389 & 32491 & 32235 & 49569 & 49386 & 32488 & 32234 & 48556 & 48352 & 32093 & 31837 \\
\hline
\end{tabular}

Note. The table reports the results of cross-sectional regressions following Fama and MacBeth (1973). The dependent variables are month $t$ log-returns on country equity indices. The independent variables are a reversal (REV) and three macroeconomic variables: inflation rate (INFL), GDP growth (GDP), and an unemployment rate $(U N E M) . \overline{R^{2}}$ denotes the average cross-sectional adjusted coefficient of determination (in \%). $N$ indicates the number of index-month observations. The values in brackets are $t$-statistics calculated according to the Newey and West (1987) method. The asterisks *, **, and *** denote statistical significance at the $10 \%, 5 \%$, and $1 \%$ levels, respectively. Panel $A$ reports the standard approach, i.e., the regressions applied to returns expressed in U.S. dollars, Panel $B$ presents the outcomes of the regressions applied to local currency returns, and Panel $C$ shows the results for the regressions on risk-adjusted returns.

value, momentum, and their combinations can be attributed to exposure to global macroeconomic risks. The loading is particularly strong for industrial production and inflation risks, among others. Furthermore, Lettau et al. (2019) discovered that the long-run reversal phenomenon is related to macroeconomic variables through the fluctuation of growth in the capital share of national income. Finally, Gracia-Feijoo and Jensen (2014) link the long-run reversal effect with the monetary environment.

To investigate the role of macroeconomic risks as potential drivers of the long-run reversal, we run two tests. First, we run Fama and MacBeth (1973) regressions including the three macroeconomic variables outlined in Section 5.4: GDP, INFL, and UNEM. We aim to ascertain whether poor past performance in returns coincides with, for example, low GDP, which would indicate that the macroeconomic risks subsume the long-run reversal effect. However, the results of this test (shown in Table 14) do not support this hypothesis. The REV variable remains a reliable negative predictor of future returns even after controlling for GDP, INFL, and UNEM. This finding remains true in different model specifications, undermining this explanation of the long-term effect based on macroeconomic risks. ${ }^{12}$

As our second test, we loosely follow the analysis of Chordia and Shivakumar (2002), who split the total returns into (i) components predicted by macroeconomic variables, and (ii) unexpected components. To this end, in the first pass we estimate index-by-index regressions of the returns for month $t$ on the global GDP growth, inflation, and unemployment rates for month $t-1$. As a proxy for these, we use cross-sectional average GDP, INFL, and UNEM variables (lagged by three months), as defined in Section 5.3. In the next pass, we obtain the predictions for months $t+1$ by combining the first stage estimates with the realizations

\footnotetext{
12 Supplementary to this, we verify our results with panel-data regressions and bivariate sorts, as in Sections 4.2 and 4.3 . These additional analyses yield consistent conclusions; for brevity, we do not report them in detail.
} 
Table 15

The long-term reversal effect in predicted and unexpected return components.

\begin{tabular}{|c|c|c|c|c|c|c|}
\hline & Low & 2 & 3 & 4 & High & H-L \\
\hline \multicolumn{7}{|c|}{ Panel A: Full study period - 1830-2019 } \\
\hline Predicted component & $\begin{array}{l}0.56^{* * *} \\
(4.35)\end{array}$ & $\begin{array}{l}0.52^{* * *} \\
(5.23)\end{array}$ & $\begin{array}{l}0.48^{* * *} \\
(9.85)\end{array}$ & $\begin{array}{l}0.67^{* * *} \\
(11.10)\end{array}$ & $\begin{array}{l}0.95^{* * *} \\
(11.89)\end{array}$ & $\begin{array}{l}0.45^{* * *} \\
(2.89)\end{array}$ \\
\hline Unexpected component & $\begin{array}{l}0.54 * * * \\
(3.13)\end{array}$ & $\begin{array}{l}0.20^{* *} \\
(1.99)\end{array}$ & $\begin{array}{l}-0.02 \\
(-0.16)\end{array}$ & $\begin{array}{l}-0.20^{* *} \\
(-2.10)\end{array}$ & $\begin{array}{l}-0.31 * * \\
(-2.22)\end{array}$ & $\begin{array}{l}-0.85^{* * *} \\
(-5.34)\end{array}$ \\
\hline \multicolumn{7}{|c|}{ Panel B: In-sample period - 1970-1999 } \\
\hline Predicted component & $\begin{array}{l}0.59 * * * \\
(5.94)\end{array}$ & $\begin{array}{l}0.62^{* * *} \\
(6.74)\end{array}$ & $\begin{array}{l}0.79 * * * \\
(9.35)\end{array}$ & $\begin{array}{l}0.97^{* * *} \\
(11.38)\end{array}$ & $\begin{array}{l}1.22^{* * *} \\
(15.04)\end{array}$ & $\begin{array}{l}0.63^{* * *} \\
(6.25)\end{array}$ \\
\hline Unexpected component & $\begin{array}{l}0.96 * * * \\
(2.90)\end{array}$ & $\begin{array}{l}0.40 \\
(1.56)\end{array}$ & $\begin{array}{l}-0.06 \\
(-0.30)\end{array}$ & $\begin{array}{l}-0.32 \\
(-1.34)\end{array}$ & $\begin{array}{l}-0.62^{* *} \\
(-2.46)\end{array}$ & $\begin{array}{l}-1.58^{* * *} \\
(-5.11)\end{array}$ \\
\hline \multicolumn{7}{|c|}{ Panel C: Pre-sample period - 1830-1969 } \\
\hline Predicted component & $\begin{array}{l}0.50 * * * \\
(3.35)\end{array}$ & $\begin{array}{l}0.44 * * * \\
(2.92)\end{array}$ & $\begin{array}{l}0.32 * * * \\
(4.76)\end{array}$ & $\begin{array}{l}0.52^{* * *} \\
(6.37)\end{array}$ & $\begin{array}{l}0.86^{* * *} \\
(8.16)\end{array}$ & $\begin{array}{l}0.43^{* * *} \\
(2.80)\end{array}$ \\
\hline Unexpected component & $\begin{array}{l}0.54 * * * \\
(2.63)\end{array}$ & $\begin{array}{l}0.21 * * \\
(2.06)\end{array}$ & $\begin{array}{l}0.06 \\
(0.65)\end{array}$ & $\begin{array}{l}-0.10 \\
(-0.82)\end{array}$ & $\begin{array}{l}-0.19 \\
(-1.13)\end{array}$ & $\begin{array}{l}-0.73^{* * *} \\
(-3.25)\end{array}$ \\
\hline \multicolumn{7}{|c|}{ Panel D: Post-sample period - 2000-2019 } \\
\hline Predicted component & $\begin{array}{l}0.90 * * * \\
(6.67)\end{array}$ & $\begin{array}{l}0.95^{* * *} \\
(7.31)\end{array}$ & $\begin{array}{l}1.07 * * * \\
(8.56)\end{array}$ & $\begin{array}{l}1.21 * * * \\
(8.42)\end{array}$ & $\begin{array}{l}1.18^{* * *} \\
(7.56)\end{array}$ & $\begin{array}{l}0.28^{* * *} \\
(2.93)\end{array}$ \\
\hline Unexpected component & $\begin{array}{l}-0.10 \\
(-0.30)\end{array}$ & $\begin{array}{l}-0.19 \\
(-0.69)\end{array}$ & $\begin{array}{l}-0.50 \\
(-1.58)\end{array}$ & $\begin{array}{l}-0.62^{* *} \\
(-1.97)\end{array}$ & $\begin{array}{l}-0.64^{*} \\
(-1.83)\end{array}$ & $\begin{array}{l}-0.54^{*} \\
(-1.69)\end{array}$ \\
\hline
\end{tabular}

Note. The table reports the mean predicted and unexpected components of returns within quintiles of equity indices from sorts on $R E V$, i.e., the average continuously compounded return in months $t-60$ to $t-13$. The study period is February $1830-J a n u a r y$ 2019 (2268 monthly observations). High and Low represent quintiles with the highest and lowest $R E V$ respectively, and $H-L$ denotes the difference between High and Low. The predicted and unexpected return components are estimated following Chordia and Shivakumar (2002), as discussed in Section 6.2. The numbers in brackets are bootstrap $t$-statistics. The asterisks *, **, and $* * *$ denote statistical significance at the $10 \%, 5 \%$, and $1 \%$ levels, respectively. The analysis is implemented in four different time periods presented in Panels A to D.

of macro variables in months $t$. In this way, we derive the predicted return components. Subsequently, we calculate the unexpected return components by subtracting the predictions from the actual returns. Finally, we form quintile portfolios in the same way as for Table 4 and compute their payoffs based on predicted and unexpected return components. In particular, we seek to verify which of the two components contributes to the long-run reversal effect: the part driven by macroeconomic exposures, or the unexpected component? The answer to this puzzle is revealed in Table 15.

Clearly, the long-run reversal effect is present only in the unexpected component. The unexpected return in the zero-investment portfolio going long (short) the quintile of indices with the highest (lowest) long-term return is negative and strongly significant, but the predicted return is actually positive. This observation does not support the hypothesis of the risk-based origin of the long-run reversal effect. Furthermore, the conclusions are similar not only for the full sample (Panel A of Table 15) and for the original sample of Balvers and Wu (2006) or Bhojraj and Swaminathan (2006) (Panel B), but also in the out-of-sample period (Panels C and D). To sum up, we find no evidence in support of the risk-based explanation of the long-run reversal effect in equity indices.

\subsection{Behavioural overreaction}

The behavioural models of long-term reversal argue that the effect emerges due to the overshooting effect caused by momentum traders (see, e.g., Hühn and Scholz (2018) or Blackburn and Cakici (2017)). For example, Hong and Stein (1999) provide evidence that momentum traders push prices of past losers below - and prices of past winners above - their inherent value. Also, Daniel et al. (1998) argue that investors become overconfident and push prices away from their fundamental value. However, the momentum profits are reversed in the long run, and this cycle is a root of the long-term reversal effect. Notably, De Bondt and Thaler (1985) in their seminal paper also link the long-term reversal with behavioural overreaction.

To check whether the long-term reversal has its roots in the overreaction of momentum traders, we run an analysis similar to Gutierrez and Prinsky (2007). If the momentum investors overreact, leading to subsequent long-term reversal, we would expect their profits to revert in the long run. However, if this hypothesis is invalid, no profit reversal should occur. As in Gutierrez and Prinsky (2007), we build momentum portfolios and observe their returns in the five years following the initial investment. The momentum strategies are represented by zero-investment portfolios, which consist of buying (selling) an equal-weighted quintile of indices with the highest (lowest) MOM. Along the lines of Jegadeesh and Titman (1993), we determine cumulative returns for the strategies in the event months, and, for robustness, we supplement it with cumulative alphas. The alphas are obtained from the eight-factor model, i.e., model (3) without the momentum factor $M O M_{t}$, which is incorporated in our test. The results of the tests are depicted in Fig. 5.

Our outcomes shown in Fig. 5 precisely match the earlier evidence, supporting the view that long-run reversal stems from momentum traders' overshooting of fundamental values. Concentrating first on the examination of the full study period (Panel A), 
5.0

0.0

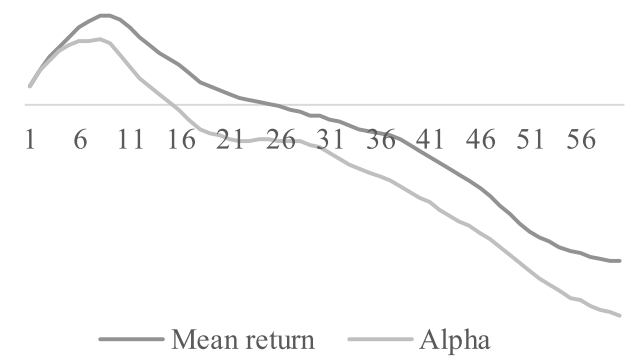

Panel A: Full Study Period, 1830-2019

4.0

2.0

0.0

$-2.0$

$-4.0$

$-6.0$

$-8.0$

$-10.0$

Panel C: Pre-Sample Period, 1830-1969
10.0

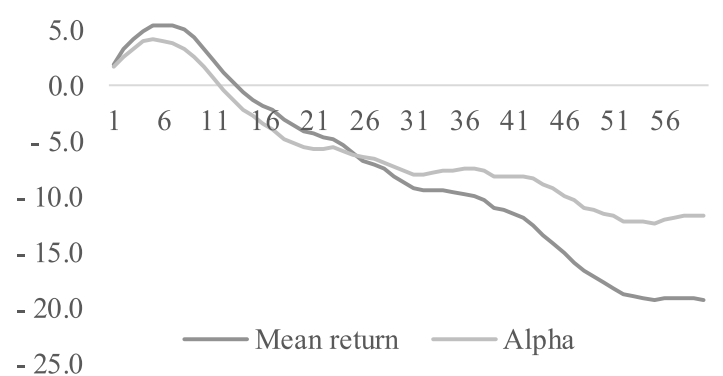

Panel B: In-Sample Period, 1970-1999

10.0

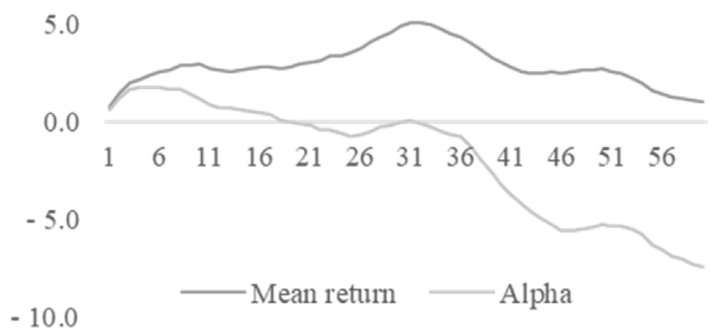

Panel D: Post-Sample Period, 2000-2019

Fig. 5. Performance of price momentum strategies through 60 months following portfolio formation. Note. The figure shows the cumulative average returns and alphas per month. The strategies represent zero-investment equal-weighted quintile portfolios going long (short) the country indices with the highest (lowest) price momentum signal, MOM, i.e., the average continuously compounded return in months $t-12$ to $t-1$. The alpha is derived from the eight-factor model identical to model (3) but excluding the momentum factor $\left(M O M_{t}\right)$. The cumulative log-returns and alphas are displayed in percentages. The analysis is implemented in four different time periods presented in Panels A to D.

we observe that the momentum profits initially increase for approximately the first 12 months, to subsequently reverse and become completely erased after about two years. Interestingly, this reversal of momentum profits is particularly pronounced in the years 1970-1999 - the original study period of Balvers and Wu (2006) and Bhojraj and Swaminathan (2006). The cumulative mean returns revert from about 5\% six months following the portfolio formation to about $-20 \%$ five years later. Notably, this period coincides with an exceptionally strong reversal effect in Fig. 4. In the earlier period of 1830-1969 (Panel C) the effect is somewhat weaker, and, consistent with this, Fig. 4 and Table 12 point to a rather unstable momentum performance over this period. Finally, the momentum reversal in Panel D, representing the most recent 20 years, is weak. In line with this pattern, Fig. 4 indicates hardly any reversal pattern over these years. To conclude, our findings corroborate the overreaction hypothesis of the long-term reversal effect in equity country indices.

\section{Concluding remarks}

Our study tests the long-run effect in equity indices in the most comprehensive dataset ever used to test this anomaly. Specifically, we analyse returns on equity portfolios from more than 71 countries for the years 1830 to 2019 and demonstrate that the long-term reversal effect is a strong and reliable pattern in the cross-section of index returns. We prove that this is an independent asset-pricing phenomenon not captured by other well-established return predictors, including the value effect measured with the dividend yield. Our results are robust to a large number of methodological considerations, including alternative formation and holding periods, the role of calendar seasonalities, and subsample analyses. Nonetheless, the long-term reversal effect is highly unstable over time and tends to vanish for decades, only to reappear again. Furthermore, it is particularly strong in periods of elevated total and idiosyncratic volatility, as well as following bullish market periods.

We are able to shed some light on the sources of long-term reversal profits. We find no support for the risk-based explanation or data mining view of this phenomenon. Our results do prove consistent with the story of behavioural overreaction. Overall, our results can provide new insights into asset pricing in financial markets and benefit quantitatively-oriented investors with a global mandate. We show that the long-run reversal is not a statistical artefact; rather, it could potentially be translated into profitable asset allocation strategies, though the long periods of consecutive losses may pose a challenge for institutional investors. 


\section{Acknowledgements}

We would like to thank Guido Baltussen, David Blitz, Kris Boudt, Nusret Cakici, and Elroy Dimson for helpful comments and suggestions. All errors remain ours. We acknowledge the support from the National Science Centre of Poland (project no. 2019/33/B/HS4/01021).

\section{References}

Ang, A., Bekaert, G., 2007. Stock return predictability: Is it there? Rev. Financ. Stud. 20 (3), 651-707.

Asness, C.S., Ilmann, A., Israel, R., Moskowitz, T.J., 2015. Investing with style. J. Portf. Manag. 13 (1), $27-63$.

Asness, C.S., Liew, J.M., Stevens, R.L., 1997. Parallels between the cross-sectional predictability of stock and country returns. J. Portf. Manag. 23 (3), $78-87$.

Asness, C.S., Moskowitz, T.J., Pedersen, L.H., 2013. Value and momentum everywhere. J. Finance 68 (3), $929-985$.

Avramov, D., Kaplanski, G., Subrahmanyam, A., 2018. Stock return predictability: New evidence from moving averages of prices and firm fundamentals. Available at SSRN: https://ssrn.com/abstract=3111334 or http://dx.doi.org/10.2139/ssrn.3111334.

Bali, T.G., Cakici, N., 2010. World market risk, country-specific risk, and expected returns in international stock markets. J. Bank. Financ. 34 , $1152-1165$.

Baltussen, G., Swinkels, L.L., van Vliet, P., 2019. Global factor premiums. Available at SSRN: https://ssrn.com/abstract=3325720 or http://dx.doi.org/10.2139/ ssrn. 3325720 .

Balvers, R.J., Wu, Y., 2006. Momentum and mean reversion across national equity markets. J. Empir. Financ. 13, 24-48.

Balvers, R., Wu, Y., Gililand, E., 2000. Mean reversion across national stock markets and parametric contrarian investment strategies. J. Finance 55 (2), 745-772. Barberis, N., Shleifer, A., Vishny, R., 1998. A model of investor sentiment. J. Financ. Econ. 49, 307-343.

Barosso, P., Santa-Clara, P., 2015. Beyond the carry trade: Optimal currency portfolios. J. Financ. Quant. Anal. 50 (5), $1037-1056$.

Baytas, A., Cakici, N., 1999. Do markets overreact: International evidence. J. Bank. Financ. 23 (7), 1121-1144.

Bhojraj, S., Swaminathan, 2006. Macromomentum: Returns predictability in international equity indices. J. Bus. 79, 429-451.

Bianchi, R.J., Drew, M.E., Fan, J.H., 2015. Combining momentum with reversal in commodity futures. J. Bank. Financ. 59, 423-444.

Blackburn, D.W., Cakici, N., 2017. Overreaction and the cross-section of returns: International evidence. J. Empir. Financ. 42 , 1-14.

Blitz, D., 2016. The value of low volatility. J. Portf. Manag. 42 (3), 94-100.

Bouman, S., Jacobsen, B., 2002. The halloween indicator, sell in may and go away: Another puzzle. Amer. Econ. Rev. 92 (5), $1618-1635$.

Brennan, M.J., Chordia, T., Subrahmanyam, A., 1998. Alternatively factor specifications, security characteristics, and the cross-section of expected stock returns.

J. Financ. Econ. 49 (3), 345-373.

Brown, S., Goetzmann, W., Ross, S., 1995. Survival. J. Finance 50 (3), 853-873.

Brunnermeier, M.K., Pedersen, L.H., 2009. Market liquidity and funding liquidity. Rev. Financ. Stud. 22 (6), $2201-2238$.

Cameron, A.C., Gelbach, J.B., Miller, D.L., 2011. Robust inference with multi-way clustering. J. Bus. Econom. Statist. 29 , $238-249$.

Chabot, B.R., Ghysels, E., Jagannathan, R., 2008. Price momentum in stocks: Insights from victorian age data. NBER Working Paper No. w14500, Available at SSRN: https://ssrn.com/abstract=1305510.

Chan, E., 2013. Mean reversion of currencies and futures. In: Algorithmic Trading: Winning Strategies and their Rationale. John Wiley \& Sons, Inc., Hoboken, NJ, USA.

Chaves, D.B., Viswanathan, V., 2016. Momentum and mean-reversion in commodity spot and futures markets. J. Commod. Mark. 3 (1), $39-53$.

Chen, A.Y., Velikov, M., 2019. Accounting for the anomaly zoo: A trading cost perspective. In: Finance Down under 2019 Building on the Best from the Cellars of Finance. Available at SSRN: https://ssrn.com/abstract=3073681 or http://dx.doi.org/10.2139/ssrn.3073681.

Chordia, T., Shivakumar, L., 2002. Momentum, business cycle, and time-varying expected returns. J. Finance 57 (2), $985-1019$.

Chui, A.C.W., Titman, S., Wei, K.C.J., 2010. Individualism and momentum around the world. J. Finance 65 (1), $361-392$.

Cooper, M.J., Gutierrez, Jr., R.C., Hameed, A., 2004. Market states and momentum. J. Finance 59 (3), $1345-1365$.

Cooper, I., Mitrache, A., Priestley, R., 2017. A global macroeconomic risk model for value, momentum, and other asset classes. Available at SSRN: https: //ssrn.com/abstract=2768040.

Daniel, K., Hirshleifer, D., Subrahmanyam, A., 1998. Investor psychology and security market under- and over-reactions. J. Finance 53, 1839-1885.

De Bondt, W.F.M., Thaler, R., 1985. Does the stock market overreact? J. Finance 40 (3), 793-805.

Dimson, E., Marsh, P., 1999. Murphy's law and market anomalies. J. Portf. Manag. 25 (2), 53-69.

Dimson, E., Marsh, P., Staunton, M., 2008. The worldwide equity premium: A smaller puzzle. In: Mehra, R. (Ed.), HandBook of the Equity Risk Premium. Elsevier, Chapter 11.

Docherty, P., Hurst, G., 2018. Investor myopia and the momentum premium across international equity markets. J. Financ. Quant. Anal. 53 (6), 2465-2490.

Fama, E.F., 2015. Cross-section versus time-series tests of asset pricing models. Fama-Miller Working Paper, Available at SSRN: https://ssrn.com/abstract=2685317 or http://dx.doi.org/10.2139/ssrn.2685317.

Fama, E.F., French, K.R., 1996. Multifactor explanations of asset pricing anomalies. J. Finance 51 (1), $55-84$.

Fama, E.F., French, K.R., 2012. Size, value, and momentum in international stock returns. J. Financ. Econ. 105, 457-472.

Fama, E.F., French, K.R., 2015. A five-factor asset pricing model. J. Financ. Econ. 116 (1), 1-22.

Fama, E.F., French, K.R., 2017. International tests of a five-factor asset-pricing model. J. Financ. Econ. 123, 441-463.

Fama, E.F., MacBeth, J.D., 1973. Risk, return, and equilibrium: Empirical tests. J. Political Economy 81 (3), $607-636$.

Fama, E.F., Schwert, G.W., 1977. Asset returns and inflation. J. Financ. Econ. 5 (2), 115-146.

Frazzini, A., Pedersen, L.H., 2014. Betting against Beta. J. Financ. Econ. 111 (1), 1-25.

French, K.R., 2019. Sorts involving prior returns. data library. Available at http://mba.tuck.dartmouth.edu/pages/faculty/ken.french/data_library.html [March 25, 2010].

Geczy, C.C., Samonov, M., 2016. Two centuries of price-return momentum. Financ. Anal. J. 72 (5), 32-56.

Geczy, C., Samonov, M., 2017. Two centuries of multi-asset momentum (equities, bonds, currencies, commodities, sectors and stocks). Available at SSRN: https://ssrn.com/abstract=2607730 or http://dx.doi.org/10.2139/ssrn.2607730.

Geczy, C.C., Samonov, M., 2019. Two centuries of commodity futures premia: Momentum, value and basis. Available at SSRN: https://ssrn.com/abstract=3336406 or http://dx.doi.org/10.2139/ssrn.3336406.

George, T.J., Hwang, C.-Y., 2007. Long-term returns reversal: Overreaction or taxes? J. Finance 62 (6), $2865-2896$.

GFD, 2019. GFD Global equity indices within the GFDIndices Database. Available at https://www.globalfinancialdata.com/gfd-indices/.

Gibbons, M.R., Ross, S.A., Shanken, J., 1989. A test of the efficiency of a given portfolio. Econometrica 57 (5), $1121-1152$.

Goetzmann, W.N., Huang, S., 2018. Momentum in imperial Russia. J. Financ. Econ. 130 (3), 579-591.

Goetzmann, W.N., Kim, D., 2018. Negative bubbles: What happens after a crash. Eur. Financial Manag. 24 (2), $171-191$.

Gracia-Feijoo, L., Jensen, G.R., 2014. The monetary environment and long-run reversals in stock retruns. J. Financ. Res. 37 (1), 3-25.

Greyserman, A., Kaminsky, K., 2014. Trend Following with Managed Futures: The Search for Crisis Alphas. Wiley, Hoboken.

Gutierrez, Jr., R.C., Prinsky, C.A., 2007. Momentum, reversal, and the trading behaviors of institutions. J. Financial Mark. 10 (1), 48-75. 
Harvey, C., 2000. The drivers of expected returns in international markets. Emerg. Mark. Q. 32-49, Available at SSRN: https://ssrn.com/abstract=795385. Hjalmarsson, E., 2010. Predicting global stock returns. J. Financ. Quant. Anal. 45, 49-80.

Hofstede, G.H., Hofstede, G.J., Minkov, M., 2010. Cultures and Organizations: Software of the Mind. McGraw-Hill Education, Maidenhead.

Hofstede Insights, 2019. Country comparison tool. Retrieved from https://www.hofstede-insights.com/country-comparison/ [March 27, 2019].

Hong, H., Stein, J., 1999. A unified theory of underreaction, momentum trading and overreaction in asset markets. J. Finance 54, $2143-2184$.

Hou, K., Peng, L., Xiong, W., 2013. Is $\mathrm{R}^{2}$ a measure of market inefficiency? Unpublished working paper available at https://wxiong.mycpanel.princeton.edu/ papers/R2pdf.

Hou, K., Xue, C., Zhang, L., 2015. Dissecting anomalies: An investment approach. Rev. Financ. Stud. 28 (3), $650-705$.

Hou, K., Xue, C., Zhang, L., 2018. Replicating anomalies. Rev. Financ. Stud. in press, Available at http://doi.org/10.1093/rfs/hhy131.

Hühn, H.L., Scholz, H., 2018. Alpha momentum and price momentum. Int. J. Financ. Stud. 6 (2), 49.

Hurst, B., Ooi, Y.H., Pedersen, L.H., 2017. A century of evidence on trend-following investing. J. Portf. Manag. 44 (1), 15-29.

Jacobs, H., 2015. What explains the dynamics of 100 anomalies? J. Bank. Financ. 57, 65-85.

Jacobsen, B., Zhang, C.Y., 2018. The halloween indicator, 'sell in may and go away': Everywhere and all the time. Available at SSRN: https://ssrn.com/abstract= 2154873 or http://dx.doi.org/10.2139/ssrn.2154873.

Jegadeesh, N., Titman, S., 1993. Returns to buying winners and selling losers: Implications for stock market efficiency. J. Finance 48 (1), 65-91.

Keloharju, M., Linnainmaa, J.T., Nyberg, P., 2016. Return seasonalities. J. Finance 71 (4), 1557-1590.

Kim, D., 2012. Value premium across countries. J. Portf. Manag. 38 (4), 75-86.

Lempérière, Y., Deremble, C., Seager, P., Potters, M., Bouchaud, J.-P., 2014. Two centuries of trend following. J. Invest. Strateg. 3 (3), $41-61$.

Lettau, M., Ludvigson, S.C., Ma, S., 2019. Capital share risk in U.S. asset pricing. J. Finance 74 (4), $1753-1792$.

Linnainmaa, J.D., Roberts, M.R., 2018. The history of the cross-section of stock returns. Rev. Financ. Stud. 31, $2606-2649$.

Long, H., Jiang, Y., Zhu, Y., 2018. Idiosyncratic tail risk and expected stock returns: Evidence from the chinese stock markets. Finance Res. Lett. 24, $129-136$.

Lubnau, T., Todorova, N., 2015. Trading on mean-reversion in energy futures markets. Energy Econ. 51, 312-319.

Malin, M., Bornholt, G., 2013. Long-term return reversal: Evidence from international market indices. J. Int. Financ. Mark. Inst. Money 25, 1-17.

McLean, R.D., 2010. Idiosyncratic risk, long-term reversal, and momentum. J. Financ. Quant. Anal. 45 (4), $883-906$.

McLean, R.D., Pontiff, J., 2016. Does academic research destroy stock return predictability? J. Finance 71 (1), 5-32.

Newey, W.K., West, K.D., 1987. A simple, positive semi-definite, heteroskedasticity and autocorrelation consistent covariance matrix. Econometrica 55 (3), $703-708$.

Patton, A., Timmermann, A., 2010. Monotonicity in asset returns: New tests with applications to the term structure, the CAPM, and portfolio sorts. J. Financ. Econ. 98 (3), 605-625.

Petersen, M.A., 2009. Estimating standard errors in finance panel data sets: Comparing approaches. Rev. Financ. Stud. 22 (1), $435-480$.

Rapach, D.E., Strauss, J.K., Zhou, G.G., 2013. International stock return predictability: What is the role of the United States? J. Finance 68 (4), 1633-1662.

Reinhart, Carmen M., Reinhart, Vincent, Trebesch, Christoph, 2016. Global cycles: Capital flows, commodities, and sovereign defaults, 1815-2015. Amer. Econ. Rev. 106 (5), 574-580.

Richards, A.J., 1997. Winner-loser reversals in national stock market indices: Can they be explained? J. Finance 52 (5), $2129-2144$.

Serban, A.F., 2010. Combining mean reversion and momentum trading strategies in foreign exchange markets. J. Bank. Financ. 34 (11), $2720-2727$.

Skoulakis, G., 2008. Panel data inference in finance: Least-squares vs. fama-macbeth. Available at SSRN: http://dx.doi.org/10.2139/ssrn.1108865.

Spierdijk, L., Bikker, J.A., van den Hoek, P., 2012. Mean reversion in international stock markets: An empirical analysis of the 20th century. J. Int. Money Finance 31 (2), 228-249.

Stivers, C., Sun, L., 2008. Cross-sectional return dispersion and the payoffs of momentum, longer-run contrarian, and book-to-market strategies. Working paper available at: http://media.terry.uga.edu/documents/finance/stivers_crosssectional_return_dispersion.pdf.

Taylor, B., 2018. Quandries over corporate actions at global financial data. Available at: https://globalfinancialdata.com/qu\{and\}ries-over-corporate-actions-atglobal-financial-data/.

Thompson, S.B., 2011. Simple formulas for standard errors that cluster by both firm and time. J. Financ. Econ. 99, 1-10.

Thomson Reuters, 2015. Datastream global equity indices. user guide. issue 5. Available at.

Umutlu, M., 2015. Idiosyncratic volatility and expected returns at the global level. Financ. Anal. J. 71 (6), 58-71.

Umutlu, M., 2019. Does idiosyncratic volatility matter at the global level? N. Am. J. Econ. Finance 47, $252-268$.

Urquhart, A., McGroarty, F., 2016. Are stock markets really efficient? evidence of the adaptive market hypothesis. Int. Rev. Financ. Anal. 47 (C), 39-49.

Vayanos, D., Woolley, P., 2013. An institutional theory of momentum and reversal. Rev. Financ. Stud. 26 (5), $1087-1145$.

Waszczuk, A., 2014. Assembling international equity datasets - review of studies on the cross-section of returns. Procedia Econ. Finance 15, $1604-1613$.

Wen, Q., 2019. Asset growth and stock market returns: A time-series analysis. Rev. Finance 23 (3), 599-628.

Zaremba, A., 2015. Has the long-run reversal reversed? evidence from country-equity indices. Rom. J. Econ. Forecast. 19 (1), $88-103$.

Zaremba, A., Bianchi, R.J., Mikutowski, M., 2019. Long-run reversal in commodity returns: Insights from seven centuries of evidence. Available at SSRN: https://ssrn.com/abstract=3314834 or http://dx.doi.org/10.2139/ssrn.3314834.

Zaremba, A., Szczygielski, J.J., 2019. And the winner is...a comparison of valuation measures for country asset allocation. J. Portf. Manag. 45 (5), 84-98. 